\title{
Catalogue of the 1997 SOHO-EIT coronal transient waves and associated type II radio burst spectra
}

\author{
A. Klassen ${ }^{1}$, H. Aurass ${ }^{1}$, G. Mann ${ }^{1}$, and B.J. Thompson ${ }^{2}$ \\ 1 Astrophysikalisches Institut Potsdam, An der Sternwarte 16, 14482 Potsdam, Germany \\ 2 Space Applications Corporation, NASA GSFC, Greenbelt, MD, U.S.A.
}

Received 14 April; accepted October 26, 1999

\begin{abstract}
We compare the coronal transient wave phenomenon discovered by SOHO extreme ultraviolet observations ("EIT waves") with the associated radio signature of a coronal shock wave (type II burst). $90 \%$ of the type II bursts are associated with an EIT wave. On average, the speed derived from the radio burst is about three times larger than the EIT wave speed. Within the sample, there is no correlation between the speeds of both tracers of a coronal disturbance. Under very general assumptions we conclude that both wave phenomena can be different signatures of the same fast magnetosonic disturbance.
\end{abstract}

Key words: Sun: corona — flares — radio radiation — shock waves

\section{Introduction}

Ultraviolett observations of the solar corona, recently obtained in several coronal emission lines by the Extreme ultraviolet Imaging Telescope onboard SOHO (EIT henceforth, Delaboudiniére et al. 1995) lead to the discovery of coronal wave transients (Moses et al. 1997; Thompson et al. 1998). Difference images of EIT snapshots reveal a bright rim sometimes nicely circularly expanding around the flaring active region (Fig. 1), sometimes only propagating in a sector of the active region surroundings but clearly influenced by magnetic structures on the propagation path.

Thompson et al. (1999) invoked that these waves may be related with the flare waves seen in the chromosphere. These Moreton waves (Moreton \& Ramsey 1960; Švestka 1976 and Ref. therein) were discovered in the early 1960s. They appear as a bright front in the center of $\mathrm{H} \alpha$ or as a dark front in the $\mathrm{H} \alpha$ wings propagating away from the flare. Moreton waves have velocities in the range

Send offprint requests to: A. Klassen, e-mail: aklassen@aip.de
$440-1125 \mathrm{~km} \mathrm{~s}^{-1}$ with a mean value of $650 \mathrm{~km} \mathrm{~s}^{-1}$. Some flare waves are invisible but their existence can be inferred indirectly by the observation of filament oscillations outside the flare region. According to Smith \& Harvey (1971) these "invisible" waves have a speed of $880 \mathrm{~km} \mathrm{~s}^{-1}$ (mean value) scattering between 410 and $2000 \mathrm{~km} \mathrm{~s}^{-1}$.

Several authors (e.g. Švestka 1976) have discussed the possibility that magnetic and thermal energy released during solar flares can escape in the form of MHD waves or shocks. A further part of the energy drives pistons (e.g. flare sprays, jets, evaporation fronts). On a larger spatial scale and a longer time scale magnetic field energy can be released as disappearing filaments and coronal mass ejections (CMEs, e.g. Kahler 1992; Hundhausen 1997)

Propagating waves and pistons are candidates for exciting coronal and interplanetary shock waves. From timing arguments (e.g. Aurass 1997), and after the discovery of flare-related radio precursors of coronal type II bursts (Klassen et al. 1999) it is evident that in the majority of cases coronal shocks have flare-related drivers. This does not exclude that a preexisting CME yields a disturbed coronal background in which a flare-related disturbance grows to a shock (Wagner \& McQueen 1983). Interplanetary shocks may well be driven by CMEs (e.g. Gopalswamy et al. 1998).

A fast mode MHD-like coronal shock wave can accelerate electrons leading to nonthermal radio emission in terms of type II bursts (Mann 1995 for a review). Type II bursts appear as slowly drifting lanes in dynamic radio spectra (the type II burst backbone component) which are superposed by a special kind of drift bursts emanating from the lanes (the herringbones). The mean coronal type II burst speed ${ }^{1}$ is in the range $765-930 \mathrm{~km} \mathrm{~s}^{-1}$ (Robinson 1985). The radio spectra show in many cases bandsplitted lanes, often multiple lanes at the fundamental, the second, sometimes also at the third harmonic

\footnotetext{
${ }^{1}$ Derived from the drift rate of the bursts and a coronal density model.
} 


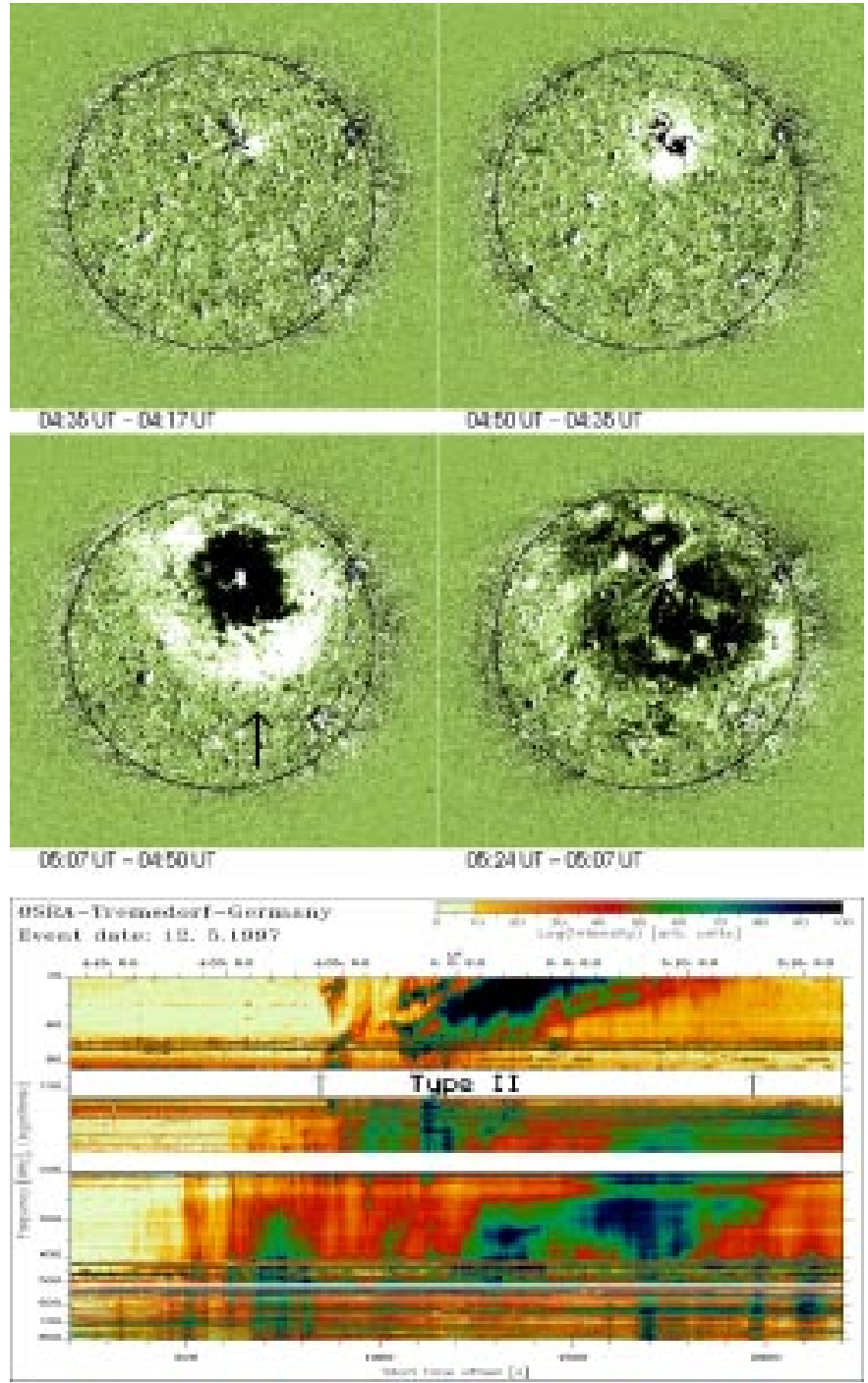

Fig. 1. The event on 12 May 1997. The top panel presents EIT $195 \AA$ running-difference images of the wave transient (arrow). North is top, east is to the left. The bottom panel shows the dynamic spectrogram in the range $40-800 \mathrm{MHz}$. Start and end of the type II burst are indicated by arrows. Bright parallel stripes are due to terrestrial disturbances

of the local plasma frequency (see Zlotnik et al. 1998). Repeated lanes in time may be due to repeated shock formation in different coronal magnetoplasma structures (Aurass et al. 1998; Klassen et al. 1999).

Moreton waves are reported to be accompanied by type II bursts (Kai 1970; Švestka 1976 and Ref. therein). It is generally accepted that both phenomena (Moreton waves and the type II bursts) are signatures of the same driving agent (Uchida 1968). In Uchida's interpretation the hydromagnetic fast mode wave propagates in the corona, and a skirt of this wave front sweeps over the chromosphere with a velocity exeeding the fast mode velocity in the chromosphere itself. Both Moreton waves and EIT transient wave events move away from the flare site and

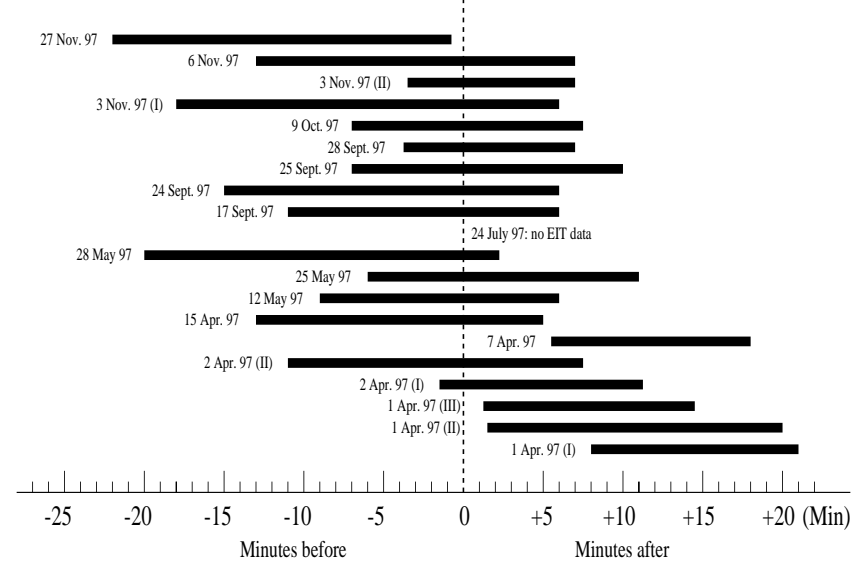

Fig. 2. EIT wave onset related with the start of associated type III bursts (indicating the start of the impulsive flare phase). The start time of the type III bursts is zero on the time axis

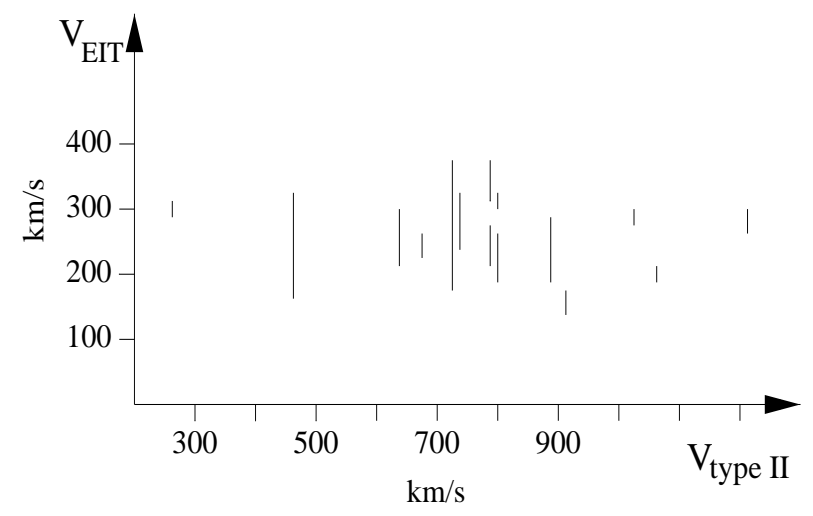

Fig. 3. The speed relation between EIT waves and type II bursts

have a reminiscent front structure. Wave fronts appear semicircular for Moreton waves and sometimes circular for EIT waves. Moreton waves represent a wave motion seen in a $10^{4} \mathrm{~K}$ plasma. EIT waves are visible in EUV spectral lines (for example FeXII, $\geq 1.610^{6} \mathrm{~K}$ ). The speed of Moreton waves $\left(>400 \mathrm{~km} \mathrm{~s}^{-1}\right)$ exceeds the speed of EIT waves $\left(170-350 \mathrm{~km} \mathrm{~s}^{-1}\right)$. There is not enough information to judge about speed changes of the wave fronts during propagation.

\section{Instruments and data selection}

The radio type II observations were obtained with the radio spectral polarimeter of the Astrophysical Institute Potsdam (Mann et al. 1992). The instrument consists of sweep-frequency spectrographs in the ranges 40-90, 100-170, 200-400 and 400-800 MHz, with a sweep rate of $10 \mathrm{~s}^{-1}$. The dynamic spectrograms were digitally recorded. Here, we present the spectra of 21 type II bursts observed in 1997 after background subtraction. Bright stripes appearing at a constant frequency are due to terrestrial disturbances. 


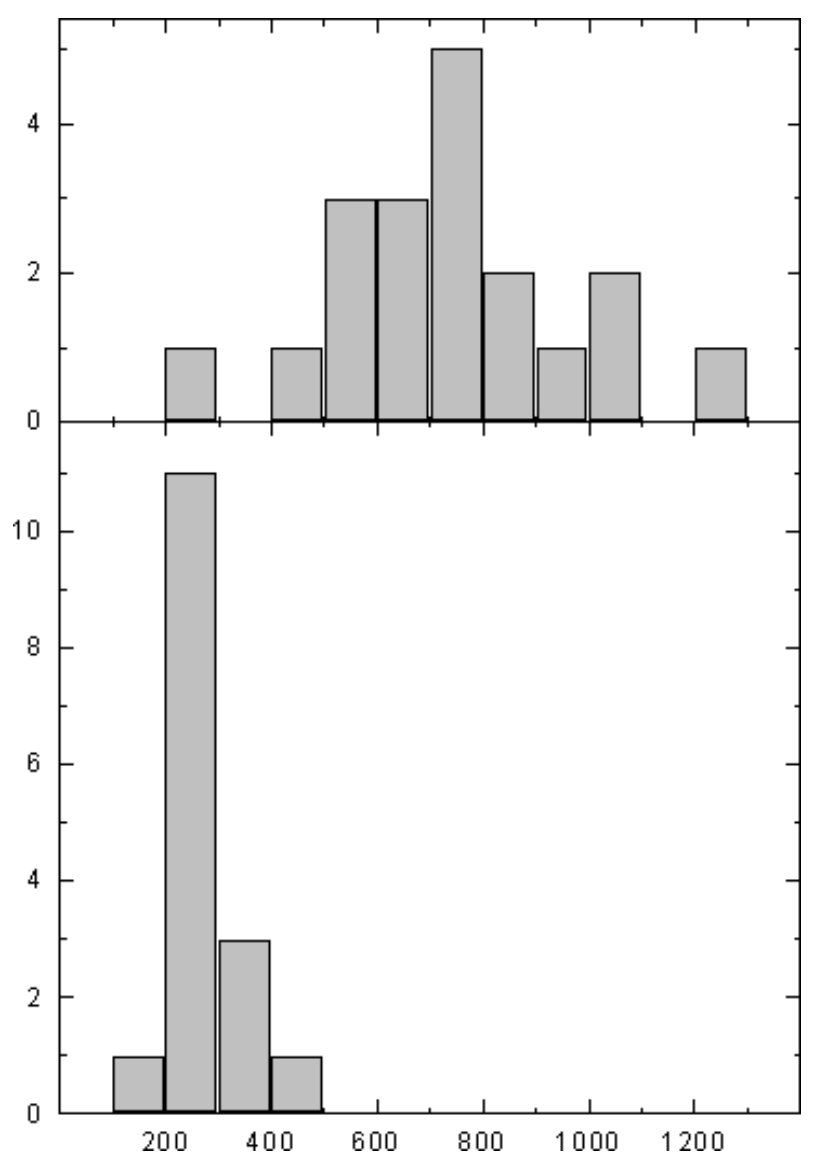

Fig. 4. Velocity histogram of type II bursts (top) and EIT waves (bottom). The mean speed of type II bursts is about three times larger than the velocity of EIT waves

The joint ESA/NASA Solar Heliospheric Observatory (SOHO) mission offers a unique set of spacebased solar observations (Fleck et al. 1995). The EIT onboard SOHO provides line observations at several temperatures. We present the $195 \AA$ (Fe XII) data, only, which is sensitive to material at approximately $1.610^{6} \mathrm{~K}$. The images were recorded on a $1024 \times 1024$ pixel $(44.2 \times$ 44.2 arcmin) CCD camera with a spatial resolution of 2.59 arcsec. Each event is presented as a series of images which have been enhanced by digitally substracting the previous image (running-difference method) after exposure time normalization. The method highlights only the changes which occur in the images, with light (dark) regions indicating areas which experienced an increase (decrease) in emission. The running difference images were examined in conjunction with the standard EIT images for evidence of propagating transient brightenings. Solar rotation correction was not necessary due to the comparatively short time interval between exposures.

In assembling the catalogue, we started with a list of type II bursts. Then the EIT data corresponding with the type II burst time intervals were examined. This led us to the discovery of some additional wave effects. Afterwards, basing on the list of EIT wave events we were able to find
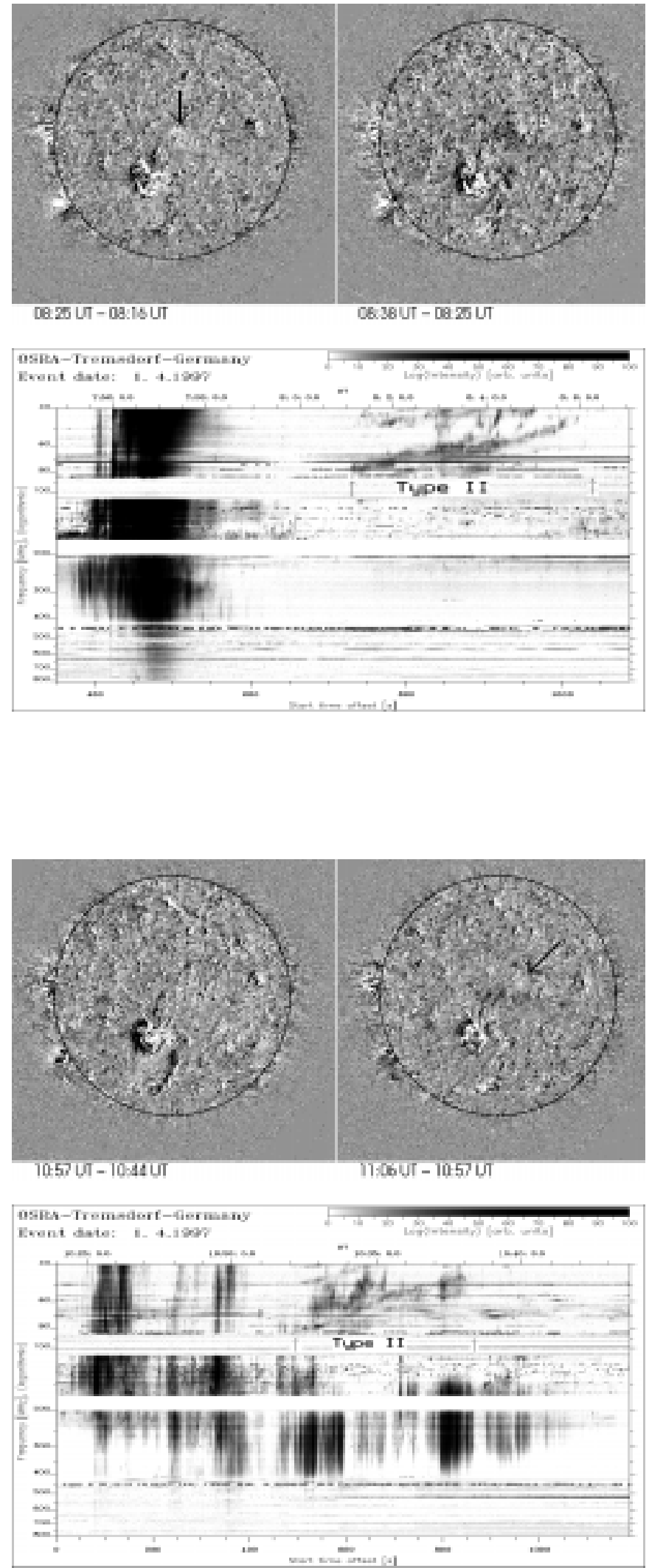

Fig. 5. Top-event I, bottom event II on 1 April 1997 

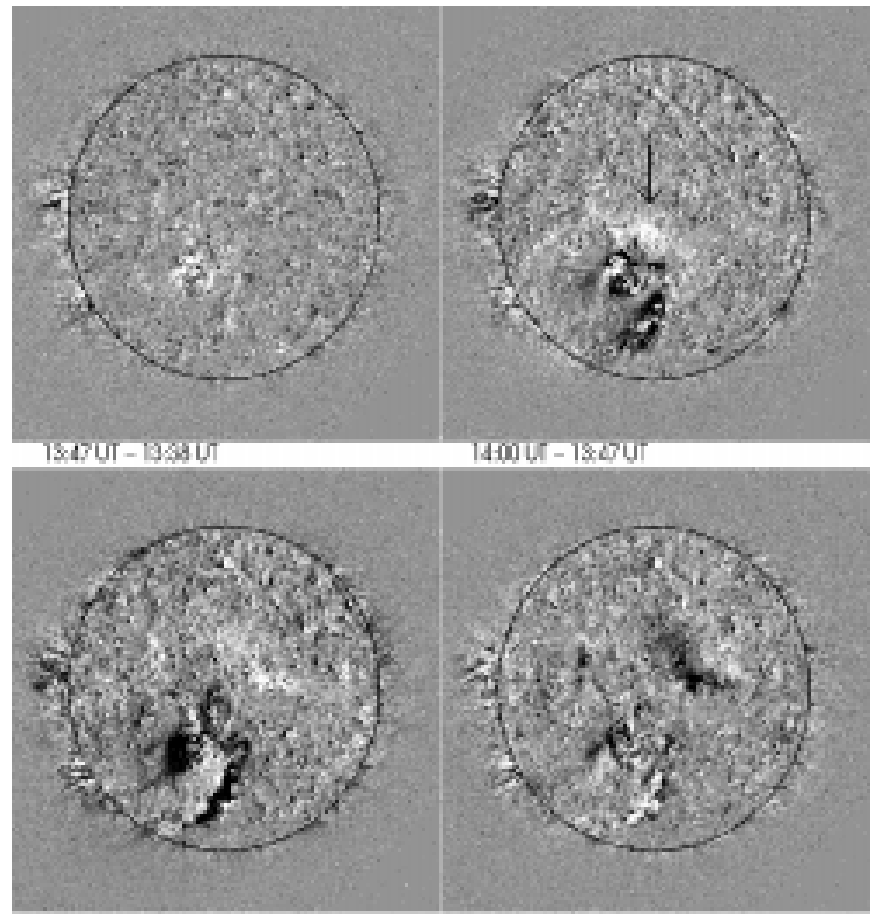

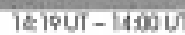

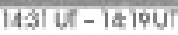

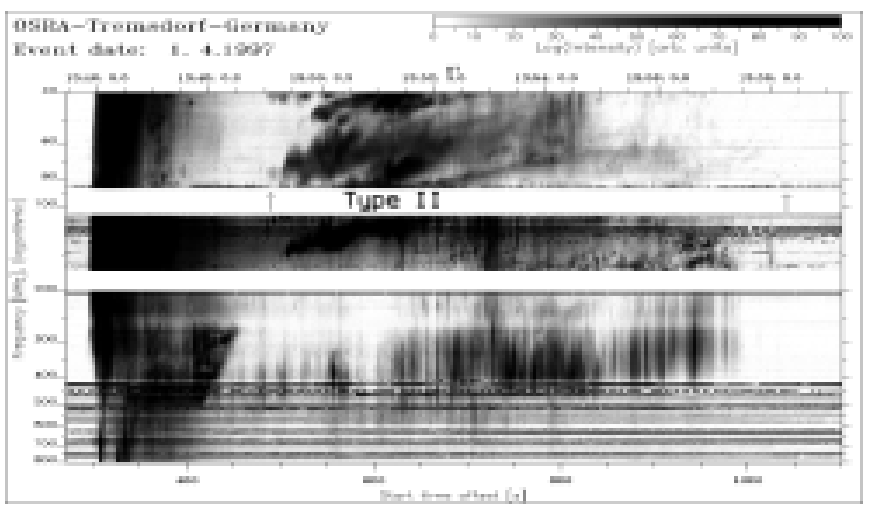

Fig. 6. Event III on 1 April 1997

some not yet identified faint type II bursts. The EIT wave event list was compiled by examining all of the $195 \AA$ data which were obtained at a high cadence (more than 1 image per 30 minutes). Data obtained at a lower cadence would be unlikely to show evidence of any wave transients.

Figure 1 shows a strong example of an EIT wave, consisting of a brightening propagating away from the flaring region. The wave is observable in (4) consecutive images, while most of the waves in this catalogue were not observed in more than two images. In some cases, a wave is only observed in a single image. Although it is most ideal if a wave observation exhibits evidence of motion, but the low image cadence and low amplitude of the brightenings can prohibit this. In the catalogue, a wave observed in a single image is listed because it has an appearance similar to waves observed in multiple images: a diffuse brightening visible in a single location for only one image, with propagation appearing to center on a flaring region.

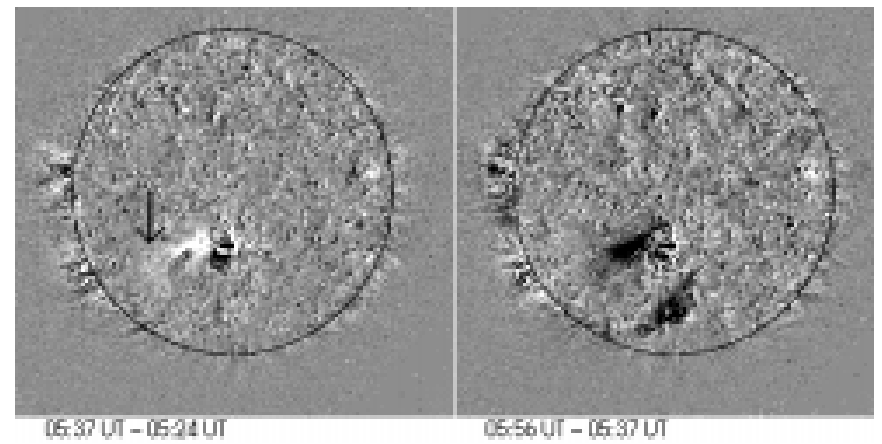

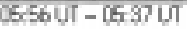
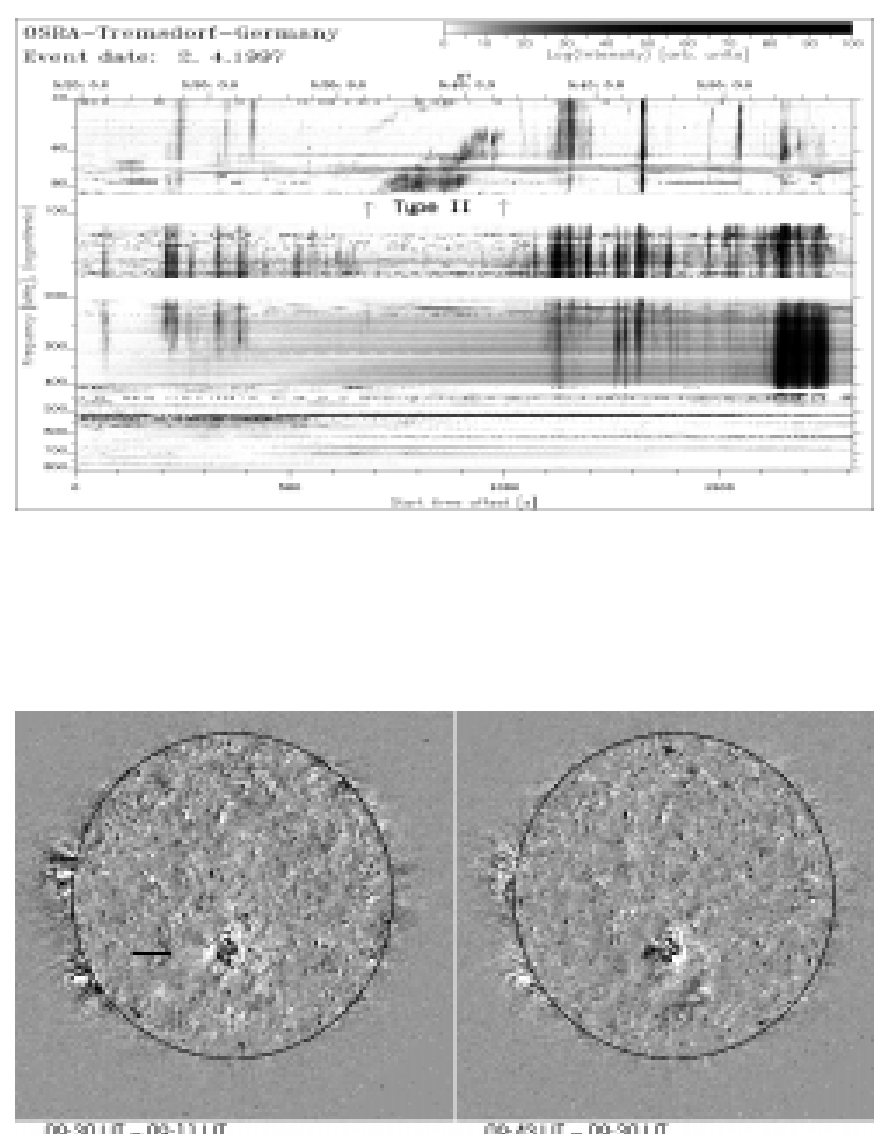

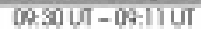

Q.630T-0.50प

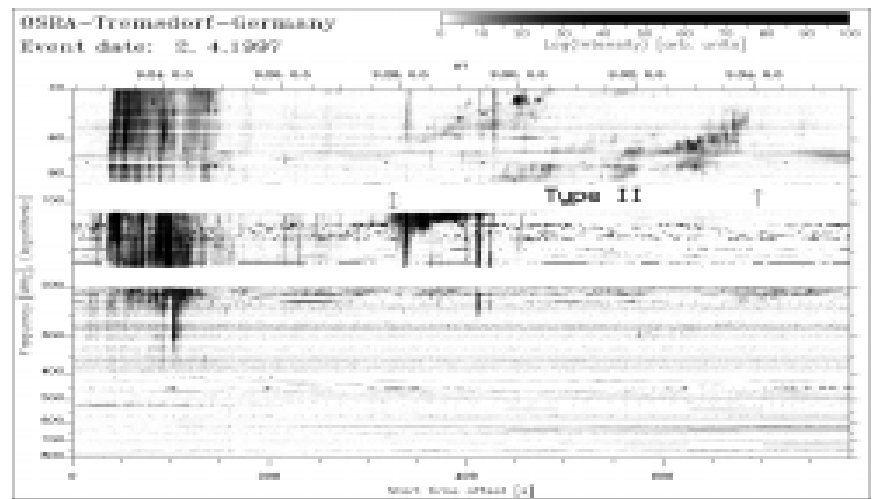

Fig. 7. Top - event I, bottom - event II on 2 April 1997 

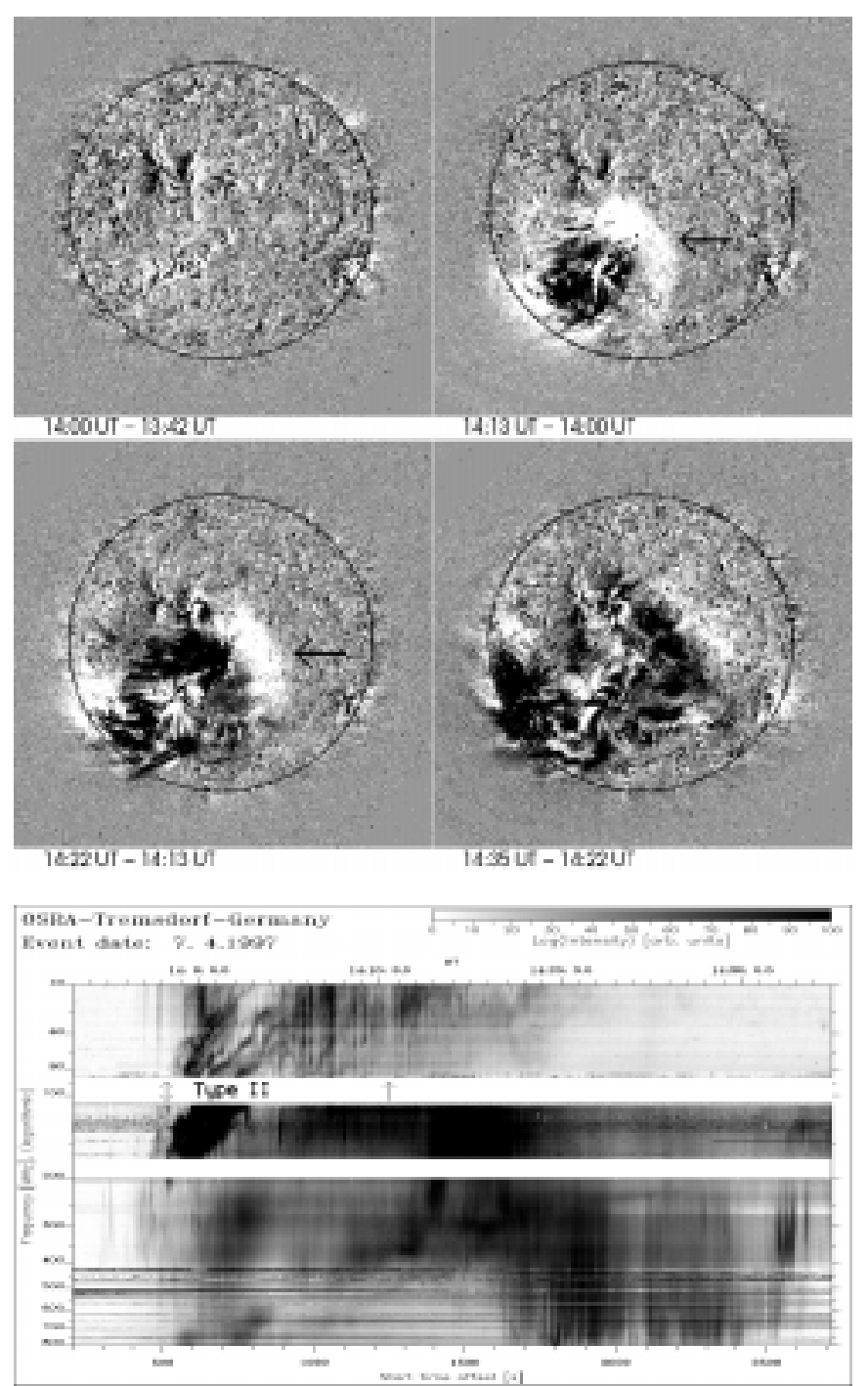

Fig. 8. Event on 7 April 1997

For supplementary information we used BATSE CGRO, Yohkoh hard X-ray, and GOES soft X-ray data provided by the Solar Data Analysis Center (SDAC) at Goddard Space Flight Center.

\section{The sample}

Table 1 presents the parameters of EIT waves, type II bursts and related flares. In the second column a start time of the events is given which demands for some comments. Due to the "rough" EIT image cadence (one image in about 15 minutes) the wave front is usually visible only at some distance from the flaring active region. It is difficult to give an exact estimate of the ignition site and time of the disturbance in EIT frames. In Table 1, "start time" means the time interval between two subsequent images within which an EIT wave appears. Further, there is a source of instrumental error involved in the recording of
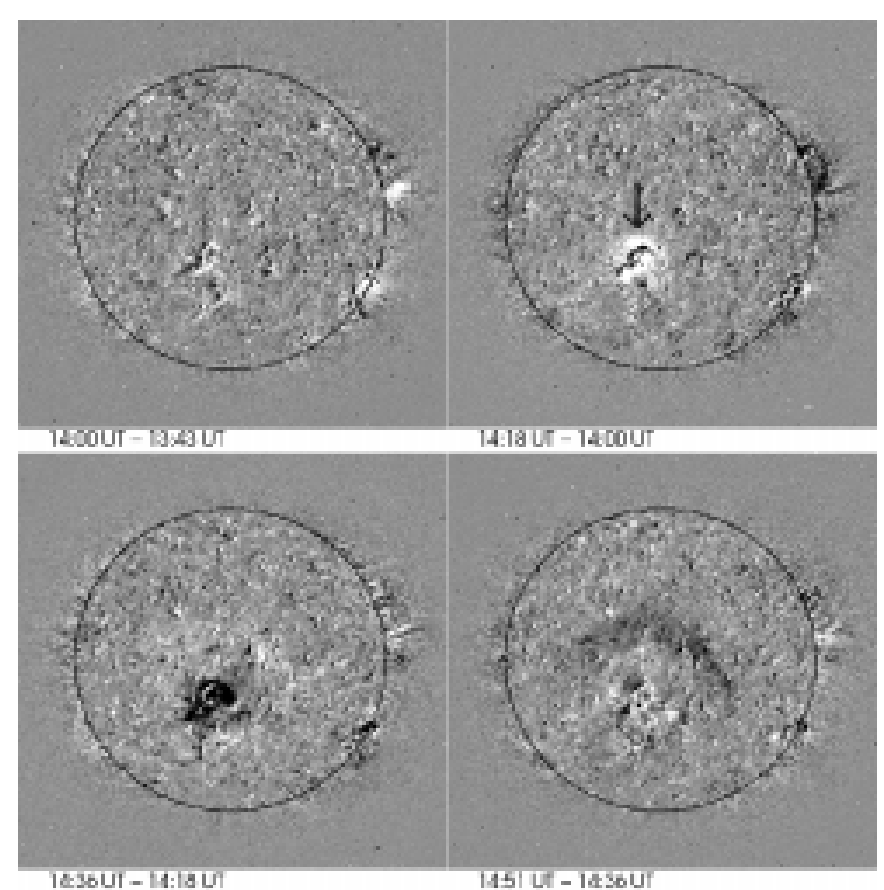

IE36U - M:I8U

$14510 t-14300$

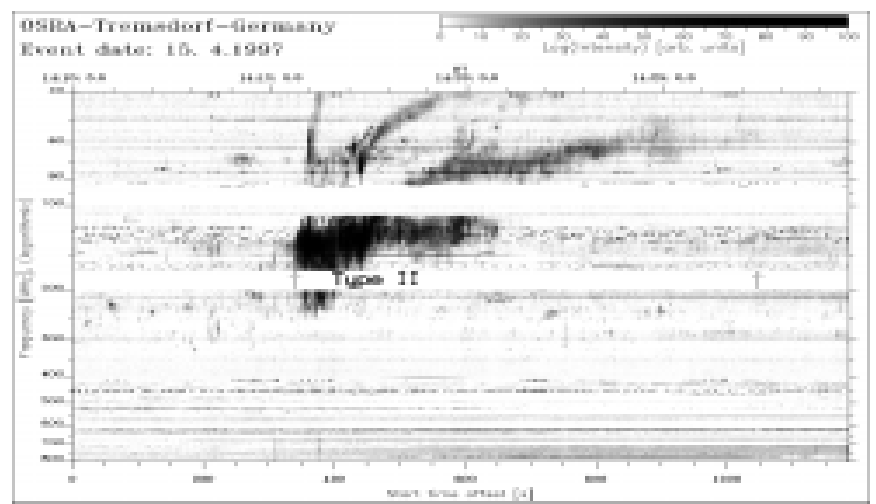

Fig. 9. Event on 15 April 1997

the EIT image time. This introduces an additional uncertainty of several minutes into image timing. Figure 2 gives the relation between the EIT image times and the flare onset reference "associated type III bursts". The black bars denote the start time window of the EIT waves.

The decay rate of EIT waves is difficult to define. The waves weaken while propagating. Often, the time interval between subsequent images can be too large to obtain subsequent images before the wave fades from observability. The EIT wave speed (third column) is estimated relative to the solar surface by measuring successive positions of the wave front on different images. When three consecutive images contain an EIT wave transient, two speeds are listed in the catalogue corresponding to two pairs of images.

Negative type II drift rates $\left(D_{f}\right)$ mean shock propagation toward lower plasma densities. In brackets, the frequency $f$ is given where $D_{f}$ has been measured. The type II shock speed $V$ is estimated using the onefold Newkirk 

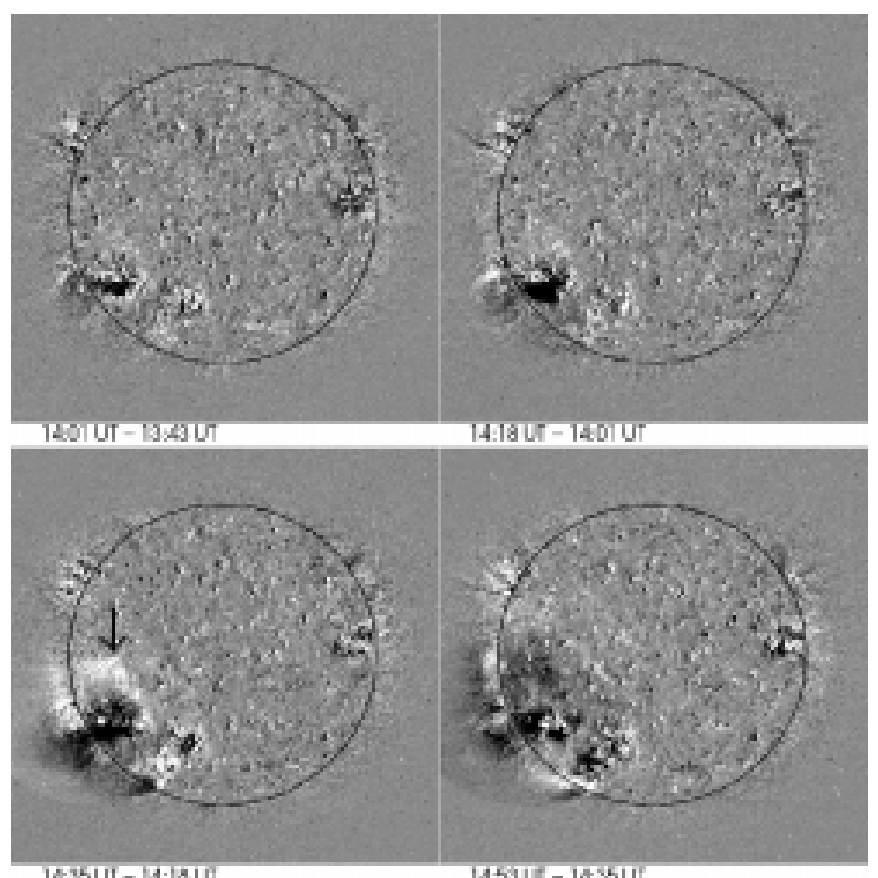

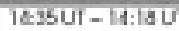

$14530 t-18550:$

OSRA-Tremedert-Germasey Krent dates as o. 1997

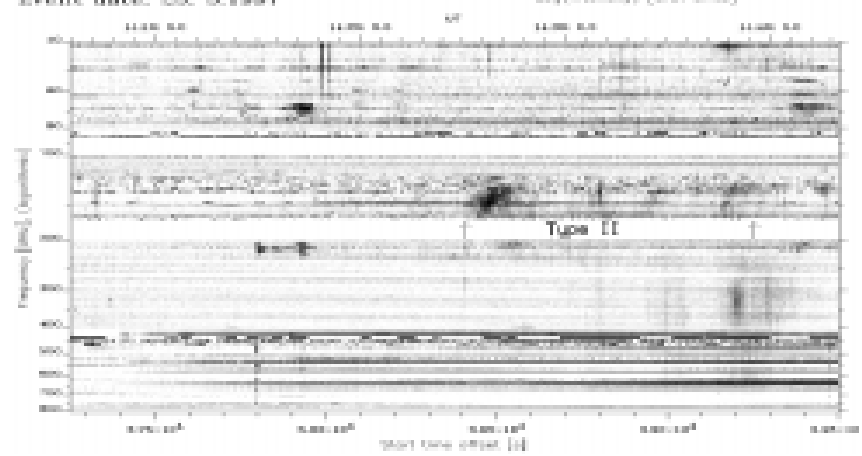

Fig. 10. Event on 25 May 1997

model $V=2 H\left(D_{f} / f\right)$ (Newkirk 1961). $H$ is the coronal density scale height radially slightly depending on the frequency $f$.

\section{Results}

1. Almost all type II bursts - 19 from 21 or $90 \%$ - are associated with EIT waves. The remaining events either do not have an EIT observation (24 July 1997) or the event starts far behind the limb (7 October 1997);

2. Some EIT waves seem to start earlier than the type II bursts. However, they ever start in the time window around associated type III bursts ${ }^{2}$ (see Fig. 2). The cadence of EIT images and uncertainties in timing are too large for a definite conclusion;

${ }^{2}$ We exclude the 27 Nov. 1997 limb event.
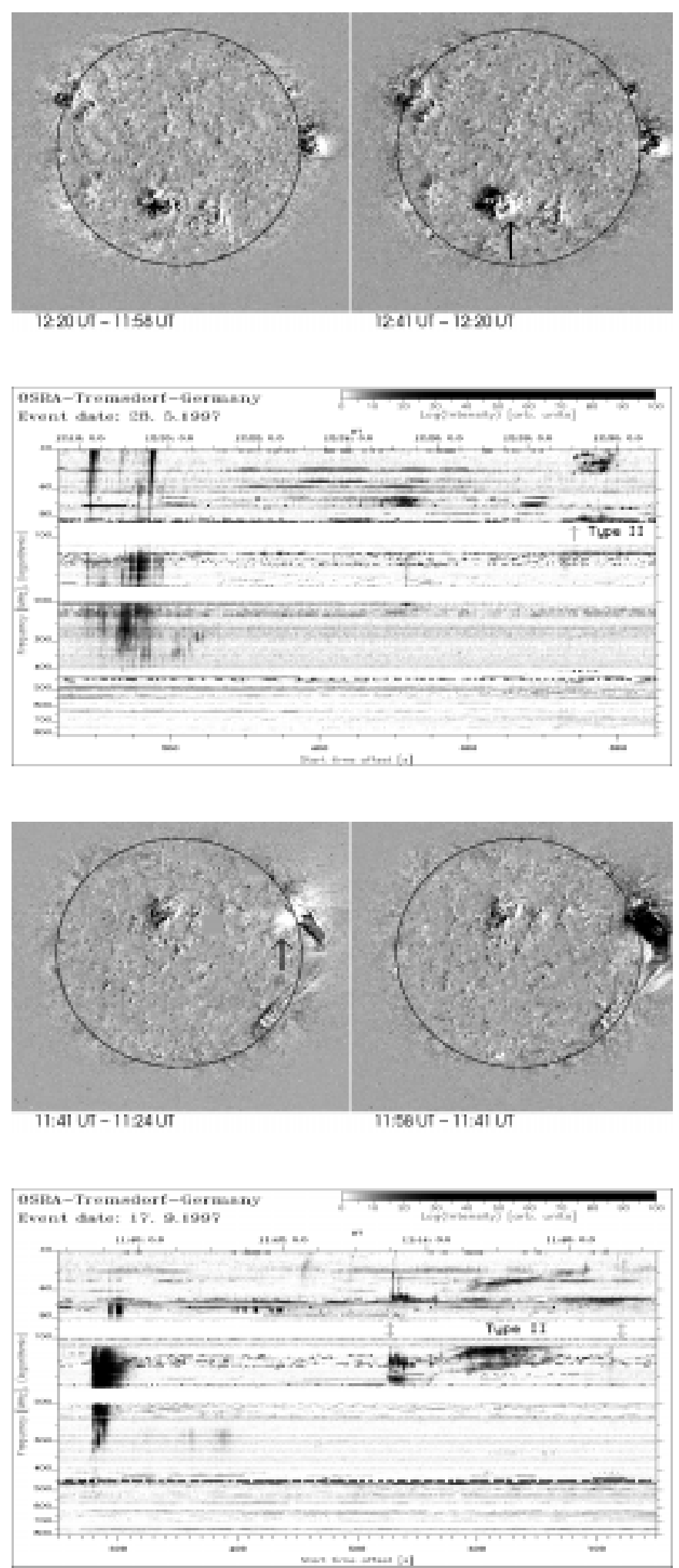

Fig. 11. Top-event on 28 May 1997, bottom event on 17 September 1997 

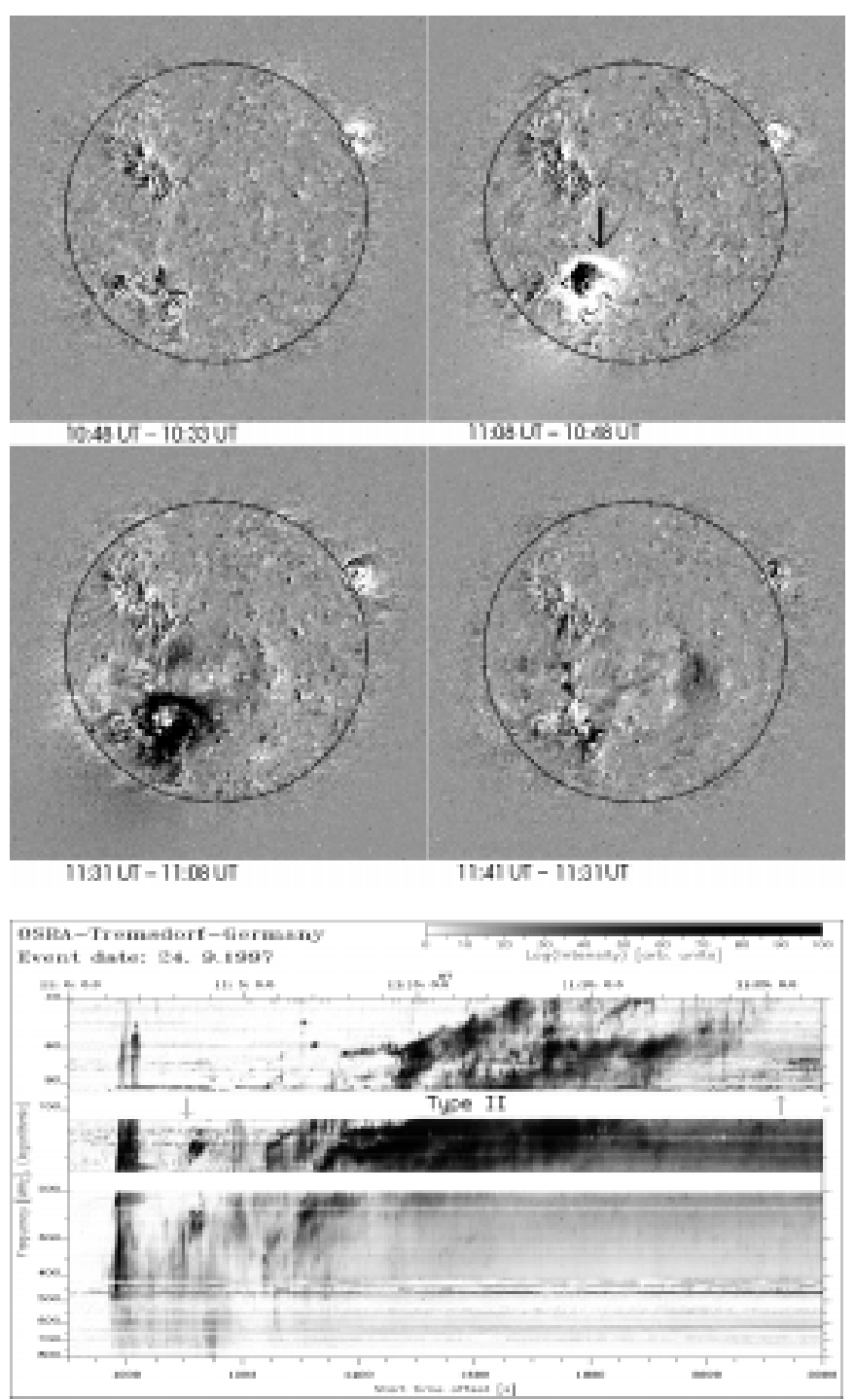

Fig. 12. Event on 24 September 1997

3. As shown in Fig. 3, the type II velocity and the EIT wave speed are uncorrelated in our sample. On average, the type II speed is about three times larger than the EIT wave speed (see Fig. 4);

4. The "best pronounced" EIT waves are observed if the type II bursts are accompanied by strong type IV emission (e.g. the cases 7 April, 12 May and 6 November 1997).
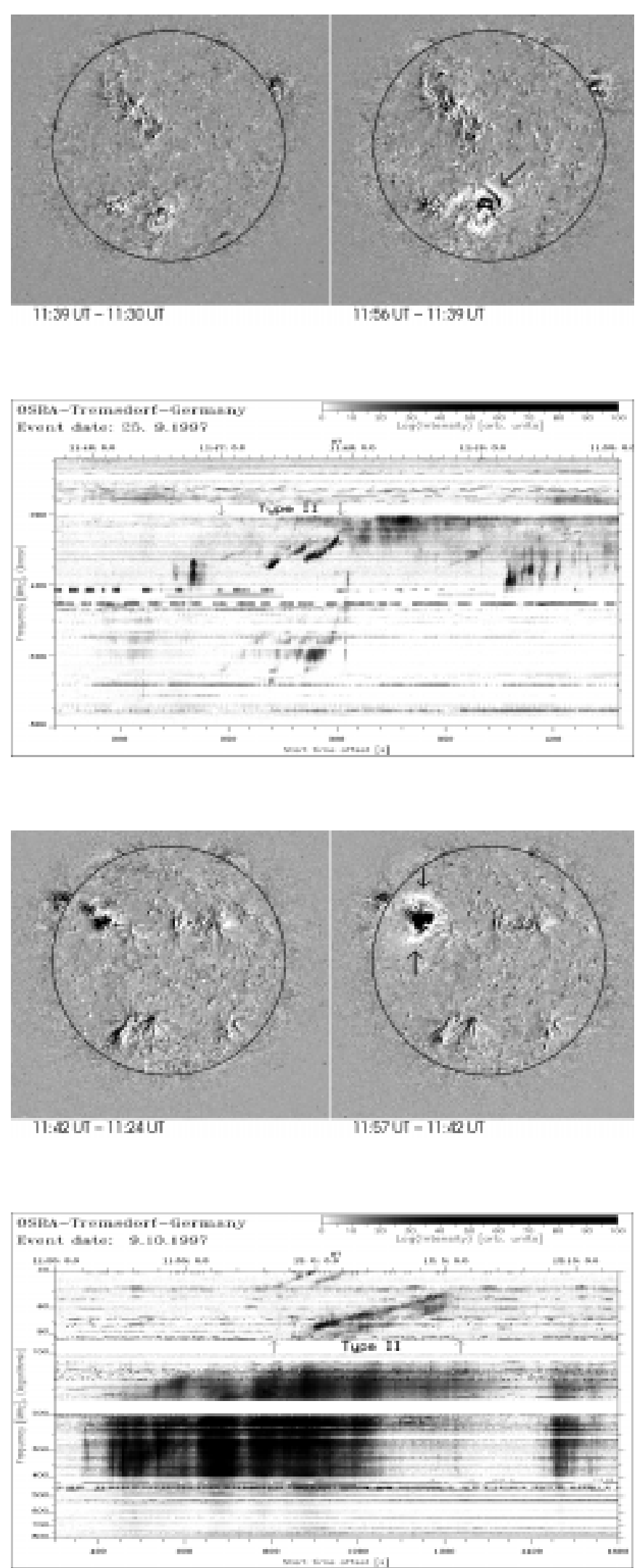

Fig. 13. Top-event on 25 September 1999, bottom event on 9 October 1997 

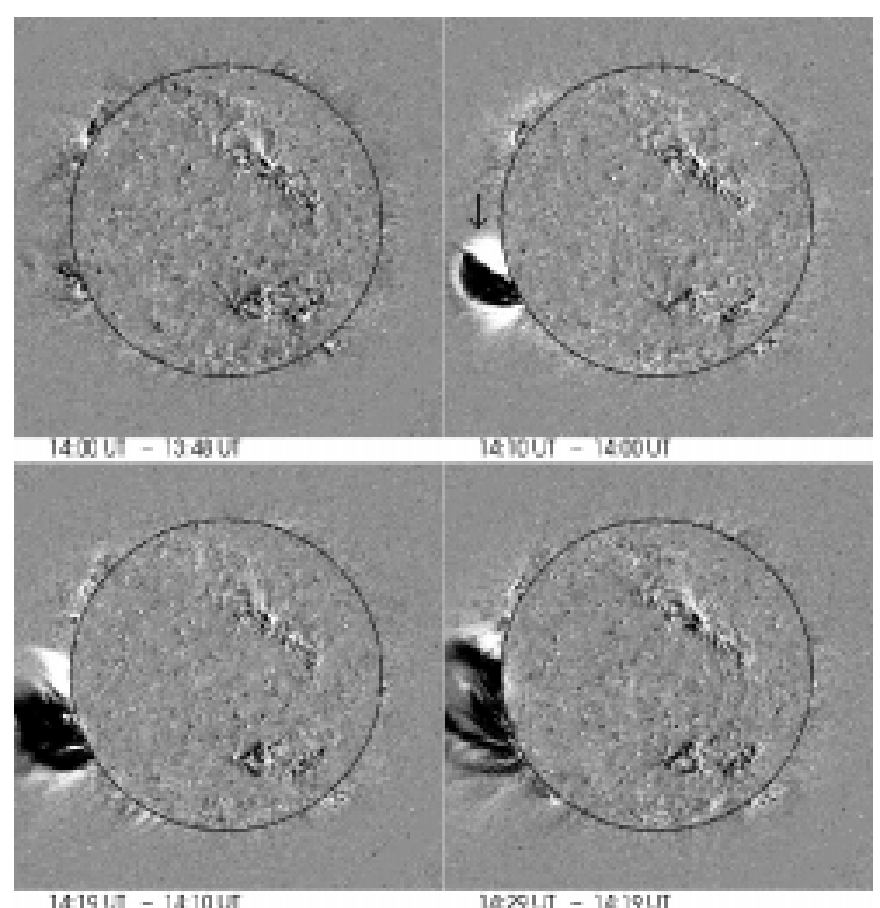

141967 - 1410U

$1420 \mathrm{UT}-121901$

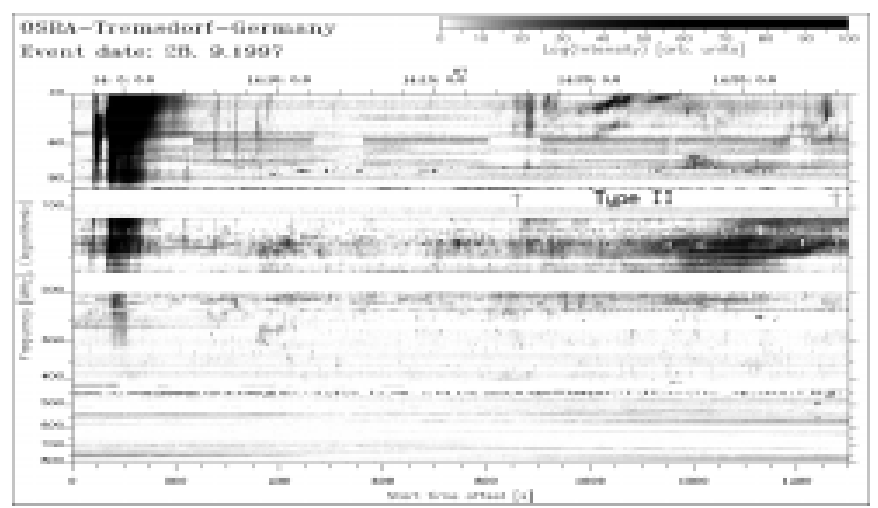

Fig. 14. Event on 28 September 1997

EIT coronal transient waves are excited in active regions. The observations demonstrate that they can propagate over the whole disc. Clearly a certain height range contributes to the visibility of the wave phenomenon. In the sense of a working hypothesis we assume an effective propagation height level of $0.08 R_{\odot}$ above the photosphere for the EIT waves. Outside active regions the background magnetic field is radially aligned. Therefore, the EIT waves propagate dominantly transversal to the magnetic field. According to Landi \& Landini (1997) the temperature of coronal plasma is $1.610^{6} \mathrm{~K}$ in active regions but $1.2510^{6} \mathrm{~K}$ in quiet regions. We assume $1.410^{6} \mathrm{~K}$ as a representative temperature value. Thus, the sound speed $^{3}$ is $c_{\mathrm{S}}=179 \mathrm{~km} \mathrm{~s}^{-1}$. The mean EIT wave speed of $271 \mathrm{~km} \mathrm{~s}^{-1}$ is significantly above the sound speed. From both facts together, we conclude that EIT waves can be regarded as fast magnetosonic ones.

\footnotetext{
${ }^{3} \gamma$ of $5 / 3$ has been used as ratio of specific heats.
}
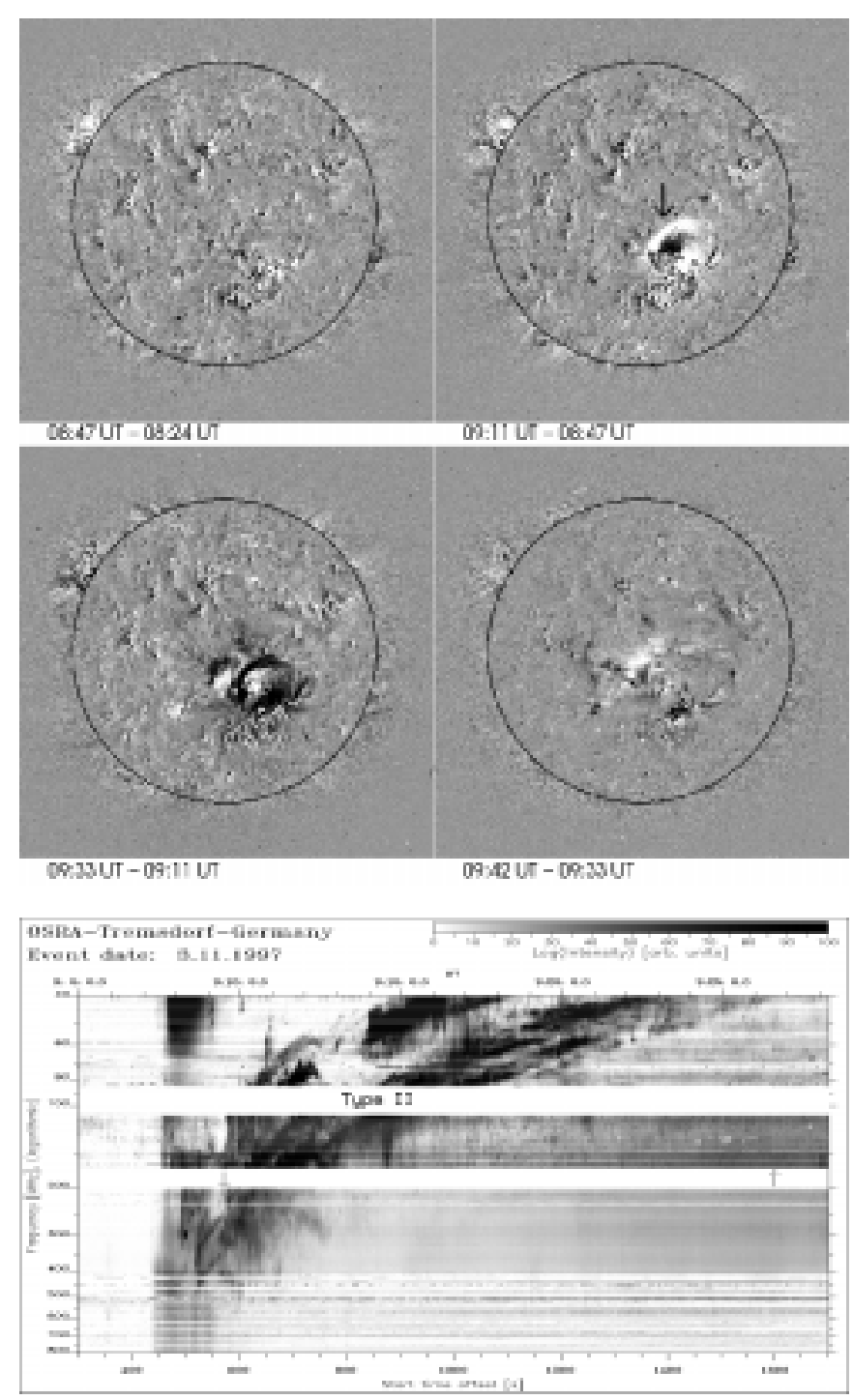

Fig. 15. Event I on 3 November 1997

The wave speed $V$ of such waves is $V=\left(v_{\mathrm{A}}^{2}+c_{\mathrm{s}}^{2}\right)^{1 / 2}$ (Priest 1982) with $v_{\mathrm{A}}$ the Alfvén speed. Then, $v_{\mathrm{A}}=$ $203 \mathrm{~km} \mathrm{~s}^{-1}$ follows as a typical value in EIT line emission regions. Outside active regions, a barometric density law (Koutchmy 1994) and a particle number density of $8.7810^{8} \mathrm{~cm}^{-3}$ (Newkirk 1961) can be assumed at the base of the corona. Therefore we find at $0.08 R_{\odot}$ from $v_{\mathrm{A}}=203 \mathrm{~km} \mathrm{~s}^{-1}$ a particle number density of $4.2210^{8} \mathrm{~cm}^{-3}$ and a magnetic field strength of $1.9 \mathrm{G}$. These values correspond with a magnetic field strength of $2.2 \mathrm{G}$ in the photosphere due to magnetic flux conservation. Such low magnetic field values are actually expected in the photosphere outside of active regions (Priest 1982). The solar type II radio bursts occur predominantly in the frequency range $40-100 \mathrm{MHz}$. According to a barometric 

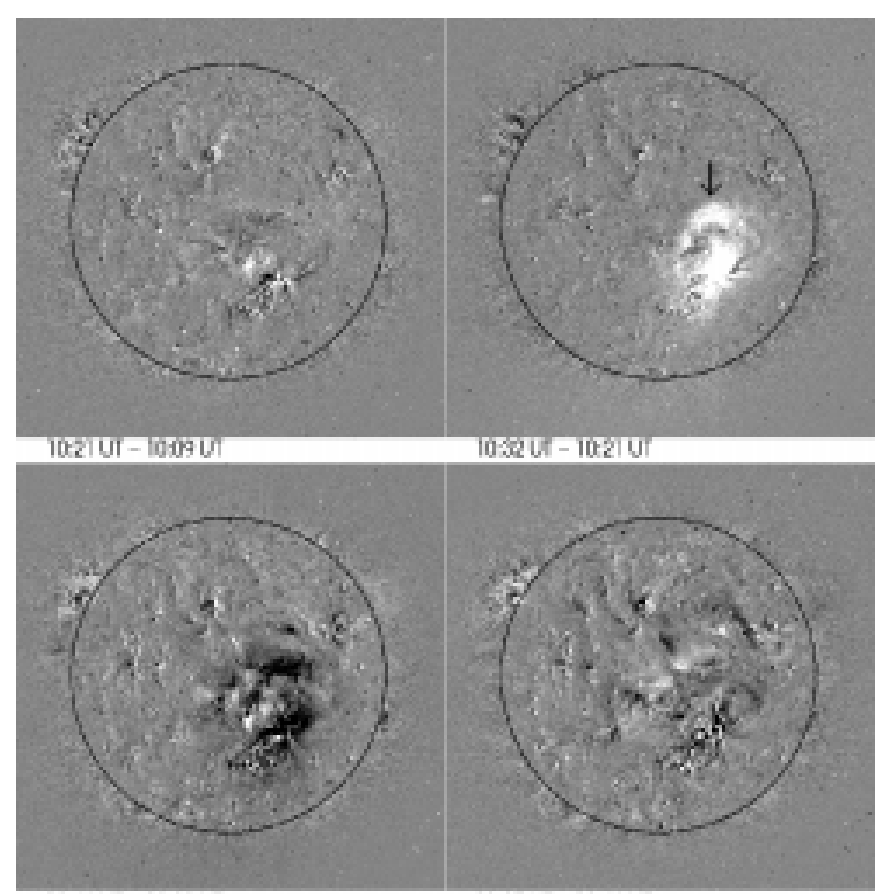

10:49UT - 10:20 UT

$1107 \mathrm{Vr}-10 \mathrm{equ}$

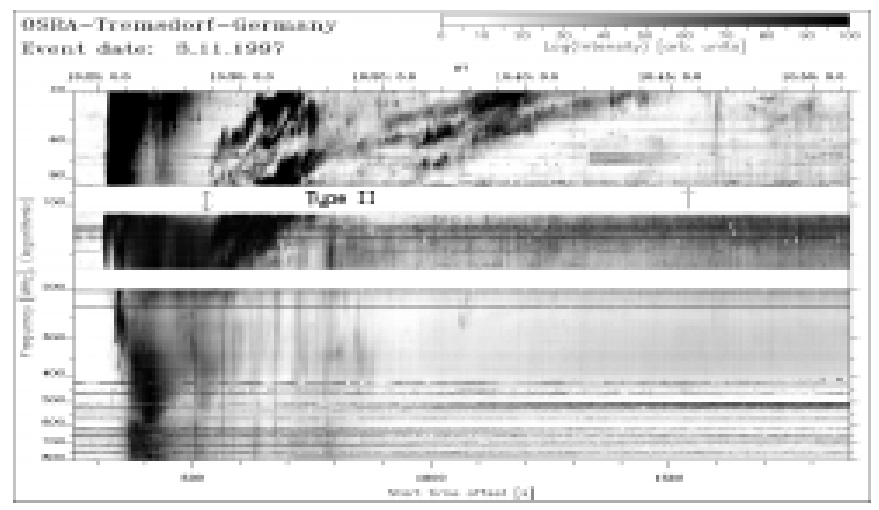

Fig. 16. Event II on 3 November 1997

density law the 100 and $40 \mathrm{MHz}$ plasma levels are located at a height of 0.35 and $0.63 R_{\odot}$, respectively ${ }^{4}$. The magnetic flux conservation provides field strengths of 1.4 and $0.8 \mathrm{G}$ leading to an Alfvén speed of 255 and $365 \mathrm{~km} \mathrm{~s}^{-1}$ in the corresponding height levels. Because solar type II bursts are excited by shock waves the driver speed has to exceed the local Alfvén speed. Just this is in agreement with our observations: the solar type II bursts point to a mean speed of $739 \mathrm{~km} \mathrm{~s}^{-1}$ well above both values.

\section{Conclusions}

From the presented relatively general estimations we find that the EIT-detected coronal transient waves and the type II exciting disturbances at larger coronal heights can

\footnotetext{
4 The radio emission is generally considered as emitted near to the local electron plasma frequency.
}
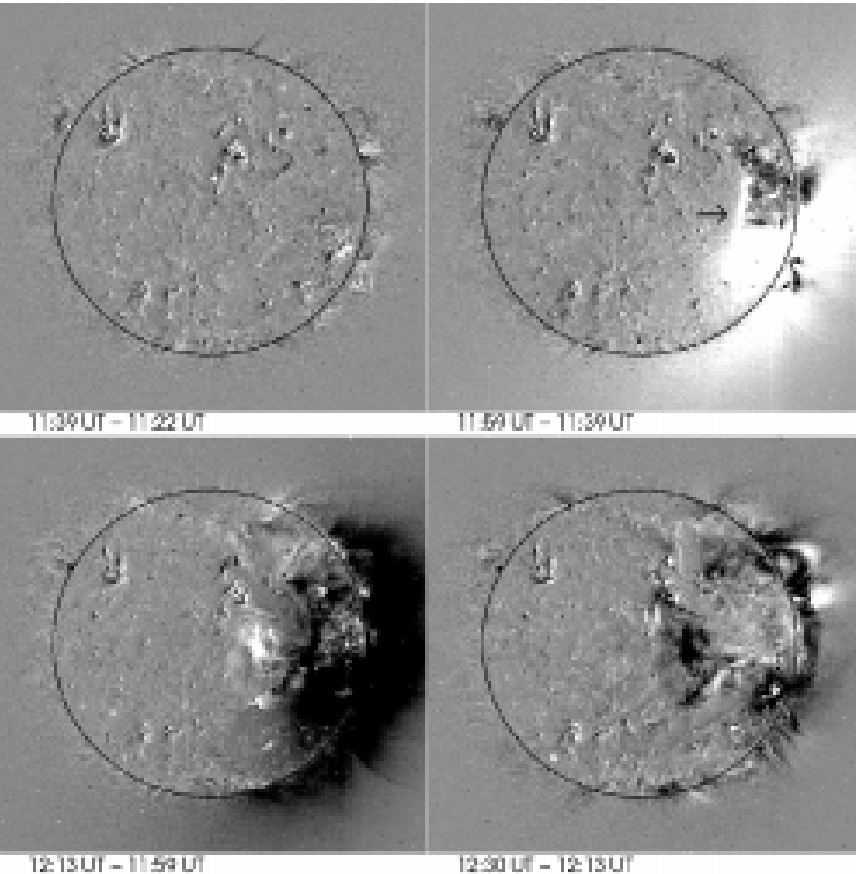

1213U-115aU

12.30u - 12130

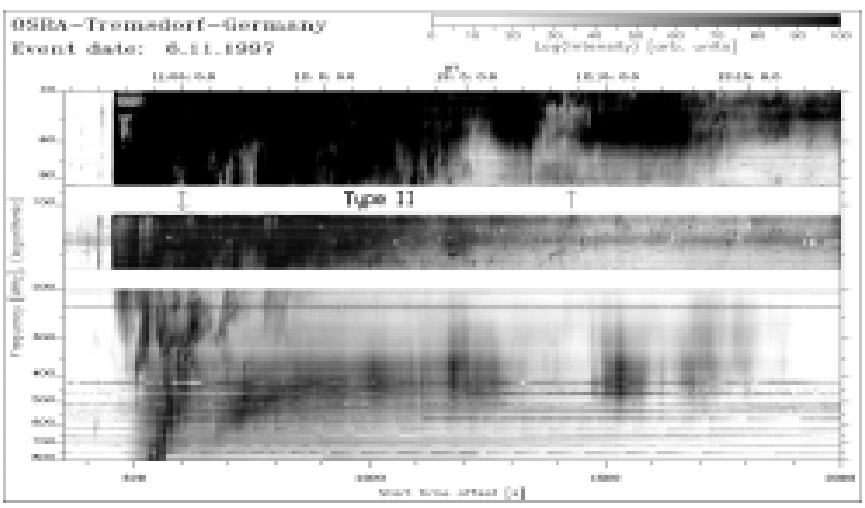

Fig. 17. Event on 6 November 1997

well be different signatures of the same fast magnetosonic wave disturbance. The observed speed difference between the mean EIT transient wave and the mean type II burst signature follows quite naturally from the inhomogenity of the density and the magnetic field in the corona, and from the magnetic flux conservation law. The relationship between the measured speed of the EIT waves and the speed derived from type II drift rates is influenced by the heights at which both are excited, and the density structure of the corona. For this reason, the speed of the type II burst cannot simply be extrapolated from the measured EIT wave speed.

Bruzek (1952, 1958) and Yajima (1971) supposed that large flares can generate a slow wave disturbance which propagates at about the velocity of sound (this was inferred from the activation of distant filaments). The corresponding velocities are between $60-200 \mathrm{~km} \mathrm{~s}^{-1}$. According to our opinion, the EIT coronal transient 

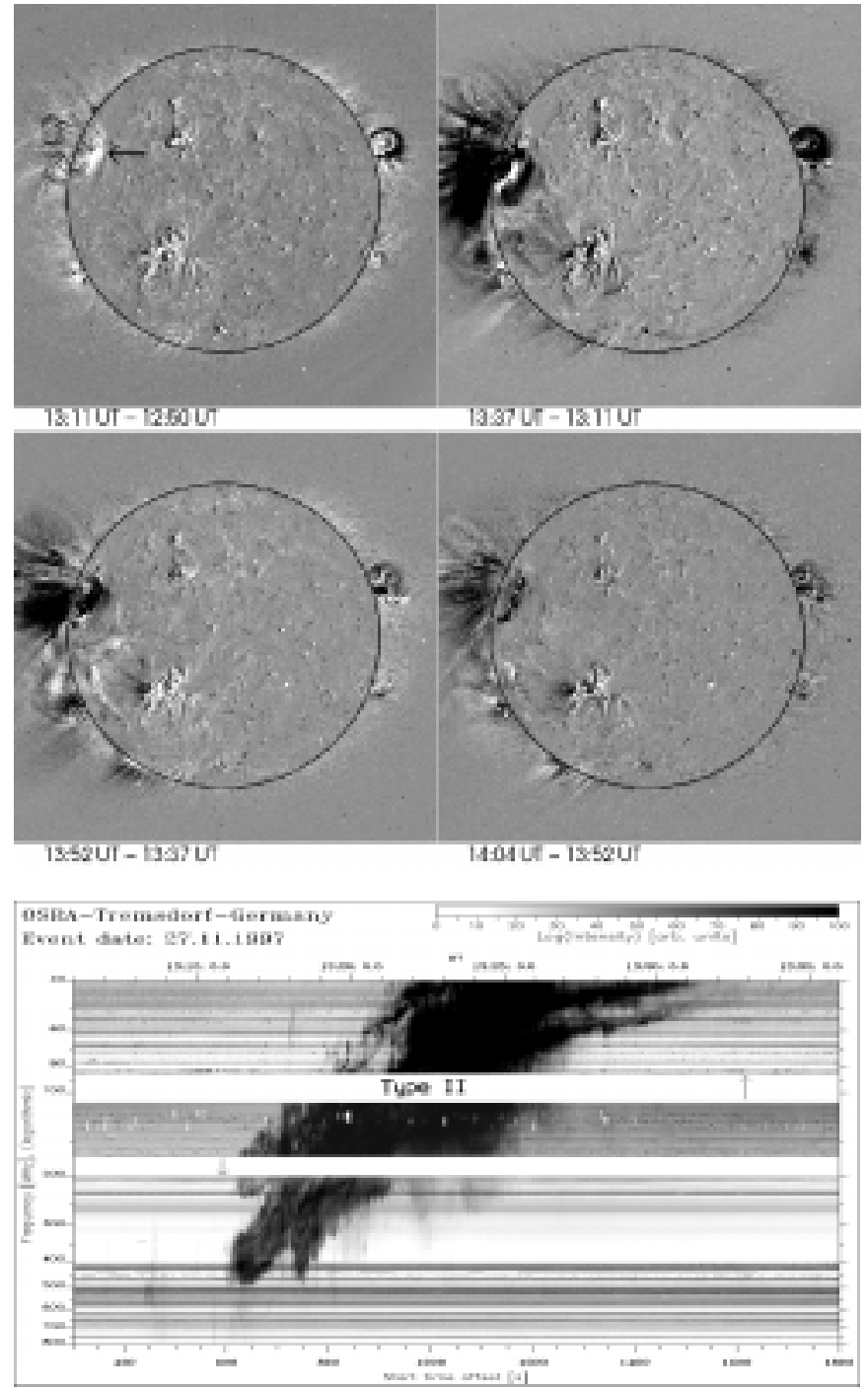

Fig. 18. Event on 27 November 1997

waves cannot be interpreted as simple acoustic waves. EIT waves are mainly propagating perpendicular to the magnetic field (what is impossible for slow magnetoacoustic waves, Priest 1982), and they are related with density compressions (otherwise inobservable). Therefore, they are more compatible with a disturbance of fast mode nature. A more detailed analysis of the data is given by Mann et al. (1999).

Acknowledgements. The authors are thankful to the referee whose remarks essentially improved the paper. Further, the authors are grateful to the staff of the solar radio observatory of the Astrophysical Institute Potsdam. The extreme ultraviolet telescope (EIT) is one of the instruments onboard the
Solar and Heliospheric Observatory (SOHO). SOHO is a joint NASA/ESA mission. The work of Andreas Klassen was paid by the Deutsche Forschungsgemeinschaft under grants DFG Au106/6-1 and Au106/6-2.

\section{References}

Aurass H., 1997, in: Lecture Notes in Physics 483, Coronal Physics from Radio and Space Observations, Trottet G. (ed.). Springer, Berlin, p. 135

Aurass H., Hofmann A., Urbarz H.-W., 1998, A\&A 334, 289

Bruzek A., 1952, Z. Astrophys. 31, 111

Bruzek A., 1958, Z. Astrophys. 44, 183

Delaboudiniére J.-P., Artzner G.E., Brunaud J., and 25 coauthors, 1995, Solar Phys. 162, 291

Fleck B., Domingo V., Poland A. (eds.), 1995, The SOHO Mission. Kluwer, Dordrecht

Gopalswamy N., Kaiser M.L., Lepping R.P., et al., 1998, JGR 103,307

Hundhausen A., 1997, in: Coronal mass ejections, Crooker N., Joselin J.A., Feynman J. (eds.), Geophysical Monograph 99, 1

Kai K., 1970, Solar Phys. 11, 310

Kahler S., 1992, ARA\&A 30, 113

Klassen A., Aurass H., Klein K.-L., Hofmann A., Mann G., 1999, A\&A 343, 287

Koutchmy S., 1994, Adv. Space Res. 14, 29

Landi E., Landini M., 1997, ESA-Journal 404, 495

Mann G., 1995, in: Lecture Notes in Physics 444, Coronal Magnetic Energy Releases, Benz A.O., Krüger A. (eds.). Springer, Berlin, p. 183

Mann G., Aurass H., Klassen A., Estel C., Thompson B.J., 1999, SOHO Workshop Paris, ESA-Journal (in press)

Mann G., Aurass H., Voigt W., Paschke J., 1992, ESA-Journal SP-348, 129

Moreton G.E., Ramsey H.E., 1960, PASP 72, 357

Moses D., Clette F., Delaboudiniére J.-P., and 32 co-authors, 1997, Solar Phys. 175, 571

Newkirk G., 1961, ApJ 133, 983

Priest E.R., 1982, Solar Magnetohydrodynamics. Reidel, Dordrecht

Robinson R.D., 1985, Solar Phys. 95, 343

Smith S.F., Harvey K.L., 1971, in: Physics of the Solar Corona, Macris C.J. (ed.), p. 156

Švestka Z., 1976, Solar Flares. Reidel, Dordrecht

Thompson B.J., et al., 1999, ApJ (in press)

Thompson B.J., Plunkett S.P., Gurman J.B., et al., 1998, JGR Lett. 25, 2465

Uchida Y., 1968, Solar Phys. 4, 30

Wagner W.J., MacQueen R.M., 1983, A\&A 120, 136

Yajima S., 1971, Tokyo Astr. Bull. 207

Zlotnik E.Ya., Klassen A., Klein K.-L., Aurass H., Mann G., 1998, A\&A 331, 1087 
Table 1. Summary of EIT, Radio, and X-ray observations

\begin{tabular}{|c|c|c|c|c|c|c|c|}
\hline Observation & $\begin{array}{l}\text { Start, } \\
\text { UT }\end{array}$ & $\begin{array}{l}\text { Peak, } \\
\text { UT }\end{array}$ & $\begin{array}{l}\text { End, } \\
\text { UT }\end{array}$ & Type & $\begin{array}{c}\text { Location (AR), } \\
\text { Range, } \mathrm{MHz}\end{array}$ & $\begin{array}{c}-D_{f} \\
\mathrm{MHz} \mathrm{s}^{-1}\end{array}$ & $\begin{array}{c}\text { Speed, } \\
\mathrm{km} \mathrm{s}^{-1}\end{array}$ \\
\hline \multicolumn{8}{|c|}{1 April (I) 1997} \\
\hline $\begin{array}{l}\text { EIT } \\
\text { RADIO: } \\
\text {-Type II } \\
\text {-Associated } \\
\text { SXR (GOES) } \\
\text { HXR (BATSE) } \\
\quad \text { (YOHKOH) }\end{array}$ & $\begin{array}{c}08: 03.3-08: 15.9 \\
08: 01 \\
07: 55 \\
07: 57 \\
\text { no obs. } \\
07: 56.6\end{array}$ & $\begin{array}{c}07: 59 \\
07: 56.7\end{array}$ & $\begin{array}{c}08: 06 \mathrm{D} \\
07: 59 \\
08: 08 \\
07: 57.4\end{array}$ & $\begin{array}{c}\text { H,HARM } \\
\text { III,DCIM } \\
\text { C2.2/SF }\end{array}$ & $\begin{array}{c}\text { S25E20 } \\
40 \mathrm{X}-90 \mathrm{U} \\
40 \mathrm{X}-800 \mathrm{X} \\
\mathrm{S} 25 \mathrm{E} 20(8026)\end{array}$ & $0.065(32)$ & $\begin{array}{c}278-189 \\
885\end{array}$ \\
\hline \multicolumn{8}{|c|}{1 April (II) 1997} \\
\hline $\begin{array}{l}\text { EIT } \\
\text { RADIO: } \\
\text {-Type II } \\
\text {-Associated } \\
\text { SXR (GOES) } \\
\text { HXR (BATSE) }\end{array}$ & $\begin{array}{c}10: 25.4-10: 43.9 \\
10: 32 \\
10: 24 \\
10: 23 \\
10: 25.2\end{array}$ & $\begin{array}{c}10: 32 \\
10: 25.6\end{array}$ & $\begin{array}{c}10: 40 \mathrm{D} \\
10: 44 \\
10: 38 \\
10: 30.6\end{array}$ & $\begin{array}{l}\text { H,HARM } \\
\text { III,DCIM } \\
\text { C2.1/SF }\end{array}$ & $\begin{array}{c}\text { S25E19 } \\
40 \mathrm{X}-90 \mathrm{U} \\
40 \mathrm{X}-800 \mathrm{X} \\
\mathrm{S} 24 \mathrm{E} 22(8026)\end{array}$ & $0.072(36)$ & $\begin{array}{c}187-265 \\
803\end{array}$ \\
\hline \multicolumn{8}{|c|}{1 April (III) 1997} \\
\hline $\begin{array}{l}\text { EIT } \\
\text { RADIO: } \\
\text {-Type II } \\
\text {-Associated } \\
\text { SXR (GOES) } \\
\text { HXR (BATSE) }\end{array}$ & $\begin{array}{c}13: 47.0-14: 00.2 \\
13: 49 \\
13: 45.8 \\
13: 43 \\
\text { no obs. }\end{array}$ & $13: 48$ & $\begin{array}{c}13: 57 \mathrm{D} \\
13: 58 \\
14: 10\end{array}$ & $\begin{array}{c}\text { G,H,HARM } \\
\text { III,DCIM } \\
\text { M1.9/1B }\end{array}$ & $\begin{array}{c}\text { S25E17 } \\
40 \mathrm{X}-160 \\
40 \mathrm{X}-800 \mathrm{X} \\
\mathrm{S} 25 \mathrm{E} 17(8026)\end{array}$ & $0.174(63)$ & $\begin{array}{c}204-275 \\
782\end{array}$ \\
\hline \multicolumn{8}{|c|}{2 April (I) 1997} \\
\hline $\begin{array}{l}\text { EIT } \\
\text { RADIO: } \\
\text {-Type II } \\
\text {-Associated } \\
\text { SXR (GOES) } \\
\text { HXR (BATSE) }\end{array}$ & $\begin{array}{c}05: 24-05: 37 \\
05: 36 \\
05: 25.6 \\
05: 29 \\
\text { no obs. }\end{array}$ & 05:30 & $\begin{array}{c}05: 41.5 \\
05: 55 \\
05: 32\end{array}$ & $\begin{array}{c}\text { H,HARM } \\
\text { III,IV,DCIM } \\
\text { C1.3/SF }\end{array}$ & $\begin{array}{c}\text { S24E11 } \\
40 \mathrm{X}-90 \mathrm{U} \\
40 \mathrm{X}-800 \mathrm{X} \\
\mathrm{S} 25 \mathrm{E} 05(8026)\end{array}$ & $0.06(37)$ & $\begin{array}{c}302-210 \\
639\end{array}$ \\
\hline \multicolumn{8}{|c|}{2 April (II) 1997} \\
\hline $\begin{array}{l}\text { EIT } \\
\text { RADIO: } \\
\text {-Type II } \\
\text {-Associated } \\
\text { SXR (GOES) } \\
\text { HXR (BATSE) }\end{array}$ & $\begin{array}{c}09: 11.5-09: 30.0 \\
\\
09: 27.5 \\
09: 22.5 \\
09: 24 \\
\text { no obs. }\end{array}$ & $09: 27$ & $\begin{array}{l}09: 34 \\
09: 30 \\
09: 42\end{array}$ & $\begin{array}{l}\text { H,HARM } \\
\text { III,DCIM } \\
\text { B6.8/SN }\end{array}$ & $\begin{array}{c}\text { S25E09 } \\
40 \mathrm{X}-130 \\
40 \mathrm{X}-450 \\
\text { S24E09(8026) }\end{array}$ & $0.0112(50)$ & $\begin{array}{c}177-378 \\
727\end{array}$ \\
\hline \multicolumn{8}{|c|}{7 April 1997} \\
\hline $\begin{array}{l}\text { EIT } \\
\text { RADIO: } \\
\text {-Type II } \\
\text {-Associated } \\
\text { SXR (GOES) } \\
\text { HXR (BATSE) } \\
\end{array}$ & $\begin{array}{c}14: 00.0-14: 12.6 \\
13: 58 \\
13: 54.3 \\
13: 54 \\
\text { no obs. } \\
\end{array}$ & 14:03 & $\begin{array}{c}14: 10 \mathrm{D} \\
16: 00 \\
15: 24\end{array}$ & $\begin{array}{c}\text { isotropic } \\
\\
\text { H,HARM } \\
\text { III,IV,DCIM } \\
\text { C6.8/2N }\end{array}$ & $\begin{array}{c}\text { S29E19 } \\
\text { 40X-250 } \\
\text { 40X-800X } \\
\text { S29E20(8027) }\end{array}$ & $0.188(66)$ & $\begin{array}{c}311-369 \\
786\end{array}$ \\
\hline \multicolumn{8}{|c|}{15 April 1997} \\
\hline $\begin{array}{l}\text { EIT } \\
\text { RADIO: } \\
\text { - Type II } \\
\text {-Associated } \\
\text { SXR (GOES) } \\
\text { HXR (BATSE) } \\
\quad \text { (YOHKOH) }\end{array}$ & $\begin{array}{c}14: 00.2-14: 18.0 \\
14: 15 \\
14: 13 \\
14: 09 \\
\text { no obs. } \\
14: 10.9\end{array}$ & $\begin{array}{c}14: 13 \\
14: 11.6\end{array}$ & $\begin{array}{c}14: 27.5 \\
14: 17 \\
14: 32 \\
\\
14: 14.40\end{array}$ & $\begin{array}{c}\text { isotropic } \\
\\
\text { H,HARM } \\
\text { DCIM } \\
\text { C1.0/SN }\end{array}$ & $\begin{array}{c}\text { S22E08 } \\
40 \mathrm{X}-250 \\
300-800 \mathrm{X} \\
\text { S24E08(8032) }\end{array}$ & $0.115(48)$ & $\begin{array}{l}307 \\
798\end{array}$ \\
\hline \multicolumn{8}{|c|}{12 May 1997} \\
\hline $\begin{array}{l}\text { EIT } \\
\text { RADIO: } \\
\text {-Type II } \\
\text {-Associated } \\
\text { SXR (GOES) } \\
\text { HXR (BATSE) }\end{array}$ & $\begin{array}{c}04: 34.9-04: 50.2 \\
\\
04: 54 \\
04: 44 \\
04: 45 \\
04: 47.7\end{array}$ & $\begin{array}{c}04: 52 \\
04: 53.9\end{array}$ & $\begin{array}{c}05: 13 \mathrm{D} \\
05: 30 \mathrm{D} \\
05: 56 \\
04: 57.6\end{array}$ & $\begin{array}{c}\text { isotropic } \\
\\
\text { H,HARM } \\
\text { III,IV,DCIM } \\
\text { C1.3/1N }\end{array}$ & $\begin{array}{c}\text { N21W08 } \\
\text { 40X-90U } \\
\text { 40X-800X } \\
\text { N21W08(8038) }\end{array}$ & $0.06(28)$ & $\begin{array}{c}289-294 \\
1029\end{array}$ \\
\hline
\end{tabular}

No obs. - no observation, $\mathrm{H}$ - Herringbones, Harm - both harmonics observed, $\mathrm{X}$ - extend beyond the instrument range, U uncertain frequency. The minus sign by the drift rate $\left(D_{f}\right)$ means shock propagation against the density gradient, in brackets the frequency is given where $D_{f}$ was measured. 
Table 1. continued

\begin{tabular}{|c|c|c|c|c|c|c|c|}
\hline Observation & $\begin{array}{l}\text { Start, } \\
\text { UT }\end{array}$ & $\begin{array}{l}\text { Peak, } \\
\text { UT }\end{array}$ & $\begin{array}{l}\text { End, } \\
\text { UT }\end{array}$ & Type & $\begin{array}{c}\text { Location (AR)/ } \\
\text { Range, } \mathrm{MHz}\end{array}$ & $\begin{array}{c}\text { Drift, } \\
\mathrm{MHz} \mathrm{s}^{-1}\end{array}$ & $\begin{array}{c}\text { Speed, } \\
\left.\mathrm{km} \mathrm{s}^{-1}\right)\end{array}$ \\
\hline \multicolumn{8}{|c|}{25 May 1997} \\
\hline EIT & 14:01.0-14:18.0 & \multirow{5}{*}{$\begin{array}{l}\text { 14:01 } \\
\text { 15:00 }\end{array}$} & \multirow{5}{*}{$\begin{array}{c}14: 39 \mathrm{D} \\
14: 43 \\
15: 16 \\
15: 52\end{array}$} & isotropic & S27E52 & \multirow{5}{*}{$>0.07(70)$} & 300 \\
\hline RADIO: & $14 \cdot 25$ & & & $\mathrm{HABM}$ & & & \multirow{4}{*}{$>267$} \\
\hline -Associated & 14:07 & & & III,DCIM & $40 \mathrm{X}-800 \mathrm{X}$ & & \\
\hline SXR (GOES) & $13: 53$ & & & B $4.8 / \mathrm{SF}$ & $\mathrm{S} 28 \mathrm{E} 50(8046)$ & & \\
\hline HXR (BATSE) & $\begin{array}{l}14: 25 \\
\text { no obs. }\end{array}$ & & & & & & \\
\hline \multicolumn{8}{|c|}{28 May 1997} \\
\hline EIT & $11: 58.2-12: 20.2$ & \multirow{5}{*}{$12: 22$} & \multirow{5}{*}{$\begin{array}{c}12: 30 \mathrm{D} \\
12: 29 \\
12: 35\end{array}$} & \multirow{5}{*}{$\begin{array}{l}\text { HARM } \\
\text { III,DCIM } \\
\text { B3.3/SF }\end{array}$} & S25E10 & \multirow{5}{*}{$\sim 0.1(50)$} & \multirow{5}{*}{$\sim 649$} \\
\hline $\begin{array}{l}\text { RADIU: } \\
\text {-Type II }\end{array}$ & $12: 29$ & & & & $40 \mathrm{X}-90 \mathrm{U}$ & & \\
\hline -Associated & $12: 18$ & & & & $40 \mathrm{X}-800 \mathrm{X}$ & & \\
\hline SXR (GOES) & $12: 00$ & & & & S28E12(8046B) & & \\
\hline HXR (BATSE) & no obs. & & & & & & \\
\hline \multicolumn{8}{|c|}{ 24 July 1997} \\
\hline EIT & no data & \multirow{5}{*}{ 13:05 } & \multirow{5}{*}{$\begin{array}{c}13: 10.5 \\
13: 20 \\
13: 11\end{array}$} & \multirow{5}{*}{$\begin{array}{l}\text { HARM? } \\
\text { III,DCIM } \\
\text { B9.1/SF }\end{array}$} & \multirow{5}{*}{$\begin{array}{c}110 \mathrm{U}-160 \\
110-800 \mathrm{X} \\
\mathrm{N} 16 \mathrm{~W} 38(8065)\end{array}$} & \multirow{5}{*}{$\sim 0.15(70)$} & \multirow{5}{*}{$\sim 572$} \\
\hline $\begin{array}{l}\text { RADIO: } \\
\text {-Type II }\end{array}$ & 13:08 & & & & & & \\
\hline - Associated & $13: 00.2$ & & & & & & \\
\hline SXR (GOES) & $12: 54$ & & & & & & \\
\hline HXR (BATSE) & no obs. & & & & & & \\
\hline \multicolumn{8}{|c|}{17 September 1997} \\
\hline EIT & $11: 23.8-11: 40.8$ & & & & N20W86 & & 239 \\
\hline $\begin{array}{l}\text { RADIO: } \\
\text {-Type II }\end{array}$ & $11: 43.4$ & & $11: 47$ & HARM & $40 X-170$ & $0.11(52)$ & 671 \\
\hline -Associated & $11: 34.7$ & & $11: 43$ & III,DCIM & $40 \mathrm{X}-800 \mathrm{X}$ & & \\
\hline SXR (GOES) & $11: 35$ & $11: 43$ & $11: 52$ & $\mathrm{M} 1.4 / \mathrm{SN}$ & N21W82(8084) & & \\
\hline HXR (BATSE) & no obs. & & & & & & \\
\hline$(\mathrm{YOHKOH})$ & 11:37.1 & $11: 42.2$ & $11: 50.2$ & & & & \\
\hline \multicolumn{8}{|c|}{ 24 September 1997} \\
\hline EIT & 10:48-11:08 & & & & S30E20 & & $317-233$ \\
\hline $\begin{array}{l}\text { RADIO: } \\
\text {-Type II }\end{array}$ & 11:03 & & $11: 20 \mathrm{D}$ & HARM & $40 X-300$ & $0.125(53)$ & 739 \\
\hline -Associated & $11: 00.8$ & & $12: 00 \mathrm{D}$ & III,IV,DCIM & $40 \mathrm{X}-800 \mathrm{X}$ & $0.120(00)$ & \\
\hline SXR (GOES) & $10: 57$ & 11:06 & $11: 10$ & $\mathrm{M} 3.0 / 1 \mathrm{~N}$ & S29E19(8088) & & \\
\hline HXR (BATSE) & 11:07E & $11: 07.5 \mathrm{E}$ & 11:10 & & & & \\
\hline & & & 25 Sept & er 1997 & & & \\
\hline EIT & $11: 39.2-11: 56.2$ & & & & S28E03 & & - \\
\hline RADIO: & $11: 46.9$ & & 11.47 .9 & HARM & $250-700$ & $3.5(320)$ & $\sim 1000$ \\
\hline -Associated & $11: 46.0$ & & 12:00D & III,IV,DCIM & $110-800 \mathrm{X}$ & & \\
\hline SXR (GOES) & $11: 40$ & $11: 49$ & $11: 55$ & C $7.2 / 1 \mathrm{~N}$ & S28E04(8088) & & \\
\hline HXR (BATSE) & $11: 44.0$ & $11: 46.1 \mathrm{U}$ & $11: 46.7 \mathrm{D}$ & & & & \\
\hline & & & 28 Septe & er 1997 & & & \\
\hline EIT & 14:00-14:10 & & & & S23E90 & & $325-167$ \\
\hline RADIO: & $14 \cdot 17.5$ & & $14 \cdot 28 \mathrm{D}$ & HARM? & $40 \mathrm{X}-60$ & $0.06(45)$ & 462 \\
\hline -Associated & 14:03.9 & & $14: 33$ & III,IV & $40 \mathrm{X}-450$ & & \\
\hline SXR (GOES) & $13: 54$ & $14: 00$ & 14:05 & B3.7/- & & & \\
\hline & 14:11 & $14: 42$ & $15: 34$ & $\mathrm{C} 1.0 /-$ & ES-limb & & \\
\hline HXR (BATSE) & no obs.?? & & & & & & \\
\hline & & & 7 Octc & r1997 & & & \\
\hline $\begin{array}{l}\text { EIT } \\
\text { RADIO: }\end{array}$ & event off & limb & tough & to see & & & - \\
\hline -Type II & $12: 47.5$ & & $12: 55$ & HARM & $40 \mathrm{X}-170 \mathrm{U}$ & $0.133(67)$ & 543 \\
\hline $\begin{array}{l}\text {-Associated } \\
\text { SXR (GOES) }\end{array}$ & $\begin{array}{c}\text { no } \\
\text { no burst }\end{array}$ & $\begin{array}{l}\text { event } \\
\text { no } \mathrm{H} \alpha\end{array}$ & & & & & \\
\hline HXR (BATSE) & no burst & & & & & & \\
\hline
\end{tabular}

No obs. - no observation, $\mathrm{H}$ - Herringbones, Harm - both harmonics observed, $\mathrm{X}$ - extend beyond the instrument range, U uncertain frequency. The minus sign by the drift rate $\left(D_{f}\right)$ means shock propagation against the density gradient, in brackets the frequency is given where $D_{f}$ was measured. 
Table 1. continued

\begin{tabular}{|c|c|c|c|c|c|c|c|}
\hline Observation & $\begin{array}{l}\text { Start, } \\
\text { UT }\end{array}$ & $\begin{array}{l}\text { Peak, } \\
\text { UT }\end{array}$ & $\begin{array}{l}\text { End, } \\
\text { UT }\end{array}$ & Type & $\begin{array}{c}\text { Location (AR)/ } \\
\text { Range, } \mathrm{MHz}\end{array}$ & $\begin{array}{c}\text { Drift, } \\
\mathrm{MHz} \mathrm{s}^{-1}\end{array}$ & $\begin{array}{c}\text { Speed, } \\
\left.\mathrm{km} \mathrm{s}^{-1}\right)\end{array}$ \\
\hline \multicolumn{8}{|c|}{9 October 1997} \\
\hline $\begin{array}{l}\text { EIT } \\
\text { RADIO: } \\
\text {-Type II } \\
\text {-Associated } \\
\text { SXR (GOES) } \\
\text { HXR (BATSE) }\end{array}$ & $\begin{array}{c}11: 42.1-11: 56.9 \\
11: 57.5 \\
11: 49.2 \\
11: 47 \\
\text { no obs.? }\end{array}$ & 12:02 & $\begin{array}{l}12: 05.7 \\
12: 11 \\
12: 18\end{array}$ & $\begin{array}{l}\text { HARM } \\
\text { IV,DCIM } \\
\text { B9.2/SF }\end{array}$ & $\begin{array}{c}\text { N23E38 } \\
40 \mathrm{X}-90 \\
110-800 \mathrm{X} \\
\text { N24E36(8092) }\end{array}$ & $0.037(32)$ & $\begin{array}{l}- \\
504\end{array}$ \\
\hline \multicolumn{8}{|c|}{3 November (I) 1997} \\
\hline $\begin{array}{l}\text { EIT } \\
\text { RADIO: } \\
\text {-Type II } \\
\text {-Associated } \\
\text { SXR (GOES) } \\
\text { HXR (BATSE) }\end{array}$ & $\begin{array}{c}08: 47.0-09: 11.5 \\
09: 09.5 \\
09: 05.3 \\
09: 03 \\
\text { no obs. }\end{array}$ & 09:10 & $\begin{array}{c}09: 27 \mathrm{D} \\
10: 00 \mathrm{D} \\
09: 13\end{array}$ & $\begin{array}{c}\text { HARM } \\
\text { III,IV,DCIM } \\
\text { M1.4/1B }\end{array}$ & $\begin{array}{c}\text { S17W18 } \\
\text { 40X-250 } \\
\text { 40X-800X } \\
\text { S18W16(8100) }\end{array}$ & $\leq 0.30(67)$ & $\begin{array}{c}276 \\
\leq 1224\end{array}$ \\
\hline \multicolumn{8}{|c|}{3 November (II) 1997} \\
\hline $\begin{array}{l}\text { EIT } \\
\text { RADIO: } \\
\text {-Type II } \\
\text {-Associated } \\
\text { SXR (GOES) } \\
\text { HXR (BATSE) }\end{array}$ & $\begin{array}{c}10: 21.2-10: 31.7 \\
10: 28.4 \\
10: 24.8 \\
10: 18 \\
\text { no obs. }\end{array}$ & $10: 29$ & $\begin{array}{l}10: 45 \mathrm{D} \\
11: 00 \mathrm{D} \\
10: 34\end{array}$ & $\begin{array}{c}\text { HARM } \\
\text { III,IV,DCIM } \\
\text { M4.2/1N }\end{array}$ & $\begin{array}{c}\text { S17W22 } \\
40 \mathrm{X}-220 \\
40 \mathrm{X}-800 \mathrm{X} \\
\mathrm{S} 17 \mathrm{~W} 22(8100)\end{array}$ & $0.224(61)$ & $\begin{array}{c}200 \\
1059\end{array}$ \\
\hline \multicolumn{8}{|c|}{6 November 1997} \\
\hline $\begin{array}{l}\text { EIT } \\
\text { RADIO: } \\
\text {-Type II } \\
\text {-Associated } \\
\text { SXR (GOES) } \\
\text { HXR (BATSE) } \\
\quad \text { (YOHKOH) }\end{array}$ & $\begin{array}{c}11: 39-11: 58.9 \\
11: 55 \\
11: 51.8 \\
11: 49 \\
12: 06.7 \mathrm{E} \\
11: 51.2\end{array}$ & $\begin{array}{c}11: 55 \\
1206: 50 \mathrm{E} \\
11: 54 \mathrm{U}\end{array}$ & $\begin{array}{c}12: 09 \mathrm{U} \\
13: 00 \mathrm{D} \\
12: 01 \\
12: 19 \\
12: 13\end{array}$ & $\begin{array}{c}\text { HARM } \\
\text { III,IV,DCIM } \\
\text { X9.4/2B }\end{array}$ & $\begin{array}{c}\text { S18W64 } \\
\text { 40X-170U } \\
\text { 40X-800X } \\
\text { S18W63(8100) }\end{array}$ & - & $\begin{array}{c}465 \\
-\end{array}$ \\
\hline \multicolumn{8}{|c|}{27 November 1997} \\
\hline $\begin{array}{l}\text { EIT } \\
\text { RADIO: } \\
\text {-Type II } \\
\text {-Associated } \\
\text { SXR (GOES) } \\
\text { HXR (BATSE) }\end{array}$ & $\begin{array}{c}12: 49.8-13: 11.2 \\
13: 15.7 \\
13: 12 \\
12: 59 \\
13: 01.2\end{array}$ & $\begin{array}{c}13: 17 \\
13: 16.0\end{array}$ & $\begin{array}{c}13: 32 \mathrm{D} \\
13: 45 \mathrm{D} \\
1320 \\
13: 24\end{array}$ & $\begin{array}{c}\text { HARM } \\
\text { DCIM,IV } \\
\text { X2.6/2B }\end{array}$ & $\begin{array}{c}\mathrm{N} 18 \mathrm{E} 64 \\
40 \mathrm{X}-500 \\
40 \mathrm{X}-800 \mathrm{X} \\
\mathrm{N} 16 \mathrm{E} 63(8113)\end{array}$ & $0.68(140)$ & $\begin{array}{c}176-138 \\
911\end{array}$ \\
\hline
\end{tabular}

No obs. - no observation, $\mathrm{H}$ - Herringbones, Harm - both harmonics observed, $\mathrm{X}$ - extend beyond the instrument range, $\mathrm{U}$ uncertain frequency. The minus sign by the drift rate $\left(D_{f}\right)$ means shock propagation against the density gradient, in brackets the frequency is given where $D_{f}$ was measured. 